Erschienen in: Anthropologie und Medialität des Komischen im 17. Jahrhundert (1580-1730), S. 429-463, https://doi.org/10.1163/9789401205993 019, Leiden, Brill, 2015

Prof. Dr. Silvia Serena Tschopp

Lehrstuhl für Europäische Kulturgeschichte

Universität Augsburg

Universitätsstr. 10

86159 Augsburg

\title{
Geschlechterkampf als Gesprächspiel. Frühneuzeitliche Ehesatire im Spannungsfeld von Affirmation und Diskursivierung sozialethischer Normen
}

$\mathrm{Zu}$ den durch die Reformation bewirkten mentalitäts- und sozialgeschichtlichen Veränderungen gehört zweifelsohne die Neubewertung der Ehe. Gegen die in der katholischen Tradition verankerte Privilegierung der Ehelosigkeit setzt Martin Luther bereits in seinen frühen Schriften den Primat der Ehe, die ihm und in seinem Gefolge auch anderen Reformatoren als gottgewollter Vollzug der Schöpfungsordnung, mithin als jene Lebensform gilt, die es überhaupt erst ermöglicht, die naturgegebene , anthropologische Konstitution' des Menschen und die biblisch fundierte Norm einer gottgefälligen Existenz in Einklang zu bringen. ${ }^{1}$ Die zahlreich veröffentlichten Ehetraktate und Hochzeitspredigten, die katechetische Literatur, die frühneuzeitlichen Erziehungs- und Hausbücher, die zeitgenössischen Dramatisierungen biblischer Stoffe oder die in Zusammenhang mit Hochzeiten verfassten Kasualdichtungen dokumentieren eindrücklich den neuen Status der Ehe und machen zugleich deutlich, mit welcher Entschiedenheit protestantische Autoren seit den 1520er Jahren daran gingen, die durch den Wittenberger Reformator begründete Eheauffassung zu popularisieren. ${ }^{2}$ Von der durch lutherische und reformierte Theologen in die Wege geleiteten Aufwertung der Ehe nun bleibt die in der Regel in den Offizinen evangelischer und gemischtkonfessioneller Reichsstädte gedruckte Flugblattpublizistik zum Thema Ehe - so scheint es - merkwürdig unberührt. Die aus dem 16. und 17. Jahrhundert überlieferten Flugblätter zeichnen im Gegenteil ein durchaus pessimistisches Bild ehelicher Verhältnisse, gestalten die Lebensgemeinschaft von Mann und Frau primär als Ort eines gewaltsam ausgetragenen Kampfes um Macht. ${ }^{3}$

Will man den Verfassern frühneuzeitlicher Flugblätter Glauben schenken, beginnen die Probleme bereits bei der Wahl eines Gatten, die in Einblattdrucken als durch Zufall bestimmt, als blinder Griff in einen „Freyerkorb“ erscheint. ${ }^{4}$ Nicht wenige Flugblätter warnen vor unüberlegter Eheschließung und schildern das Elend eines gegen den Rat der Eltern zustande gekommenen Connubium caecum ${ }^{5}$ oder warnen mit satirischen Mitteln vor den Gefahren, die

\footnotetext{
${ }^{1}$ Vgl. dazu zuletzt Erik Margraf: Die Hochzeitspredigt der Frühen Neuzeit. Mit einer Bibliographie der selbständig erschienenen Hochzeitsdrucke der Herzog-August-Bibliotehk Wolfenbüttel, der Staats- und Stadtbibliothek Augsburg und der Universitätsbibliothek Augsburg. München 2007, S. 49-118.

${ }^{2}$ Einen Überblick über das reichhaltige Eheschrifttum vermittelt: Repertorium deutschsprachiger Ehelehren in der Frühen Neuzeit. Bd. I/1: Handschriften und Drucke der Staatsbibliothek zu Berlin/Preußischer Kulturbesitz (Haus 2). Hrsg. von Erika Kartschoke. Berlin 1996. Zwei weitere angekündigte Bände sind noch nicht erschienen. Stellvertretend für eine Reihe einschlägiger Publikationen desselben Autors sei hier noch die Studie von Rüdiger Schnell: Frauendiskurs, Männerdiskurs, Ehediskurs. Textsorten und Geschlechterkonzepte in Mittelalter und Früher Neuzeit. Frankfurt/M. 1998, genannt.

${ }^{3}$ Vgl. dazu ausführlicher Joy Wiltenburg: Disorderly Women and Female Power in the Street Literatur of Early Modern England and Germany. Charlottesville und London 1992.

${ }^{4}$ Vgl. beispielsweise Deutsche illustrierte Flugblätter des 16. und 17. Jahrhunderts. Hrsg. von Wolfgang Harms. Band II: Die Sammlung der Herzog August Bibliothek in Wolfenbüttel. Kommentierte Ausgabe. Teil 1: Ethica. Physica. Hrsg. von Wolfgang Harms und Michael Schilling zusammen mit Barbara Bauer und Cornelia Kemp. Tübingen 1985, Nr. 93.

${ }^{5}$ Vgl. beispielsweise Harms/Schilling (wie Anm. 4), Nr. 24.
} 
Erschienen in: Anthropologie und Medialität des Komischen im 17. Jahrhundert (1580-1730), S. 429-463, https://doi.org/10.1163/9789401205993 019, Leiden, Brill, 2015

eine Verbindung zwischen Gatten ungleichen Alters mit bringt. ${ }^{6}$ Die überwiegende Mehrzahl der Flugblätter thematisiert allerdings die Schwierigkeiten, die sich dann ergeben, wenn die gottgewollte Ordnung der Geschlechter, die, von der Suprematie des Mannes ausgehend, von der Frau Unterwerfung unter den Willen ihres Ehegatten fordert, auf den Kopf gestellt wird. Zahlreich sind die Einblattdrucke, in denen die Herrschsucht der Frauen satirisch denunziert und die leidvollen Erfahrungen geknechteter Ehemänner beklagt werden. Zwar trifft die Kritik auch den unter der Fuchtel seiner Gattin stehenden Pantoffelhelden. So überreicht ihm etwa ein „Herr Vbersie“ Eier als Symbole der Weiblichkeit und gibt ihn damit der Lächerlichkeit preis, ${ }^{7}$ und Der groß Maulet Hund warnt die Ehemänner, sich von ihren Frauen unterjochen zu lassen, da sie sonst Gefahr liefen, von ihm verschlungen zu werden. ${ }^{8}$ Der Fokus der satirischen Angriffe richtet sich jedoch in erster Linie gegen die Frauen, die in der frühneuzeitlichen Publizistik im Rückgriff auf seit der Antike tradierte misogyne Topoi beschrieben werden. ${ }^{9}$ Besonderer Beliebtheit erfreuten sich dabei der literarische Typus des ,bösen Weibs' sowie der in zahlreichen Darstellungen begegnende Bildkomplex des ,Kampfes der Frauen um die Hosen'. ${ }^{10}$

Große Verbreitung dürfte ein erstmals 1609 erschienenes, in mehreren Nachdrucken und Varianten überliefertes Flugblatt gefunden haben, das den siegreichen Kampf eines bösen Weibes gegen den Teufel thematisiert. ${ }^{11}$ Dass es diesem gelungen sei, innerhalb einer Stunde an die dreitausend Teufel zu verwunden, wertet der Verfasser als Beweis für die Unmöglichkeit, einer widerborstigen Frau beizukommen. In einer Reihe von Antithesen beschreibt er den Eigensinn böser Weiber und ruft die Männer dazu auf, sich vor einer derartigen Frau zu hüten. Der Text schließt mit einer scherzhaften Aufzählung sprechender Namen, die für jene weibliche „Companÿ“ stehen, aus denen sich tyrannische Gattinnen rekrutierten. Der Verfasser des genannten Flugblatts beschränkt sich allerdings nicht darauf,

\footnotetext{
${ }^{6} \mathrm{Zu}$ nennen wären hier insbesondere dem Motivbereich des senex stultus zugehörige Einblattdrucke wie beispielsweise Harms/Schilling (wie Anm. 4), Nr. 111. Auch die Verbindung zwischen einer älteren Frau und einem jungen Mann ist Gegenstand satirischer Darstellung (vgl. etwa einen 1570 in Nürnberg erschienenen Einblattdruck, der zeigt, wie eine alte Frau sich um einen Jüngling bemüht. Der Holzschnitt ist abgebildet in Eduard Fuchs: Illustrierte Sittengeschichte vom Mittelalter bis zur Gegenwart. Bd. 1: Renaissance. München [1909], S. 201, Nr. 176).

${ }^{7}$ Vgl. Illustrierte Flugblätter aus den Jahrhunderten der Reformation und der Glaubenskämpfe. Hrsg. von Wolfgang Harms. Bearbeitet von Beate Rattay. Coburg 1983, Nr. 131. Zum Pantoffelhelden als Motiv schwankhafter Überlieferung vgl. Dietz-Rüdiger Moser: Schwänke um Pantoffelhelden oder die Suche nach dem Herrn im Haus. Volkserzählungen und ihre Beziehungen zu Volksbrauch, Lied und Sage. In: Fabula. Zeitschrift für Erzählforschung 14 (1973), S. 205-292.

${ }^{8}$ Vgl. William A. Coupe: The German Illustrated Broadsheet in the Seventeenth Century. Historical and Iconographical Studies. Vol. 2: Bibliographical Index. With 145 Plates. Baden-Baden 1967, Nr. 71.

${ }^{9}$ Zur misogynen Tradition der Frauen- und Ehesatire vgl. Horst Langer: „Weiber“-Schelte, „Weiber“-Lob. Zum Frauenbild in den Prosasatiren von Moscherosch bis Beer. In: Zeitschrift für Germanistik N.F. 2 (1992), S. 355366; Barbara Becker-Cantarino: Johann Beers „Weiber-Hächel“ und die Tradition der Ehe- und Frauensatire. In: Johann Beer. Schriftsteller, Komponist und Hofbeamter 1655-1700. Beiträge zum Internationalen BeerSymposion in Weißenfels Oktober 2000. Hrsg. von Ferdinand van Ingen und Hans-Gert Roloff. Bern 2003 (= Jahrbuch für Internationale Germanistik A70), S. 443-456; Ulrike Gaebel: Malus mulier. Weibliche Rede in Eheund Zuchtdialogen der Frühen Neuzeit. In: Böse Frauen - Gute Frauen. Darstellungskonventionen in Texten und Bildern des Mittelalters und der Frühen Neuzeit. Hrsg. von Ulrike Gaebel und Erika Kartschoke. Trier 2001 (= Literatur - Imagination - Realität 28), S. 299-316.

${ }^{10}$ Zum Topos des , bösen Weibs' vgl. Franz Brietzmann: Die böse Frau in der deutschen Litteratur des Mittelalters. Berlin 1912 (= Palaestra 42).

${ }^{11}$ Die wohl älteste, auf das Jahr 1609 datierte Fassung ist abgedruckt in Coupe (wie Anm. 8), Nr. 24. Vgl. auch Harms/Schilling (wie Anm. 4), Nr. 152, und Die Einblattdrucke der Universitätsbibliothek Erlangen-Nürnberg. Hrsg. von Christina Hofmann-Randall. Erlangen 2003 (= Schriften der Universitätsbibliothek ErlangenNürnberg 42), S. 356, A X 2. Zur Verbreitung des genannten Einblattdrucks vgl. William A. Coupe: The German Illustrated Broadsheet in the Seventeenth Century. Historical and Iconographical Studies. Vol. 1: Text. Baden-Baden 1966, S. 53f., sowie den Kommentar in Harms/Schilling (wie Anm. 4), S. 310, der zehn Varianten nennt.
} 
Erschienen in: Anthropologie und Medialität des Komischen im 17. Jahrhundert (1580-1730), S. 429-463, https://doi.org/10.1163/9789401205993 019, Leiden, Brill, 2015

vor weiblichen Eheteufeln zu warnen, sondern rät seinen männlichen Lesern außerdem, wie sie sich ihrer bösen Weiber entledigen könnten: „Man nehme ein Weib nur auff ein Jahr Gefellts einem dann, so behalt ers gar, Jst sie aber böß, so nimbs beym Haar, Vnd Wirff sie dann die Stiegen hinab". ${ }^{12}$ Auf die Frage, wie mit widerständigen Ehefrauen umzugehen sei, versuchen gleich mehrere Einblattdrucke eine Antwort zu geben. Ein $k=$ stlich gutes bewertes Recept/vor die M(nner/ so b=se Weiber haben empfiehlt lakonisch: „Hastu ein böses Weib am Sontag So fahr ins Holtz am Montag Vnd haw Bengel am Dinstag Schlag dapfer drauf am Mitwoch So wirdt sie kranck am Donnerstag Vnd legt sich gewiß am Freÿtag Stirbt sie dann am Sambstag So begrebst du sie am Sontag Vnd darauf machst ein gutn Montag. "13 Das Züchtigungsrecht des Mannes illustriert variantenreich $S c h=n / K=$ stliche vnd bewehrte Recept/fФr die Regier vnd Mons $\Phi$ chtigenn $b=$ sen Faulen/vnartigen/Weiber, das die Laster der Frau - Schwatzhaftigkeit, Faulheit, Eitelkeit, Verschwendung, Streitsucht - geißelt und deren Bestrafung mittels Schlägen schildert. ${ }^{14}$ Auch Offt Probiertes und Bewährtes Recept oder Artznë̈ für die bösse Kranckheit der unartigen Weiber setzt auf die Prügelstrafe und verweist auf die acht Tierhäute, die der Gatte seiner Frau herunter schlagen müsse. ${ }^{15}$ Das auf einen Schwank von Hans Sachs zurückgehende Motiv der acht Tierhäute, aus denen die Bösartigkeit von Ehefrauen erwachse, findet sich auch in Kurtze Beschreibung Der neunh(utigen Weiber, einem Flugblatt, das schildert, wie ein Mann seiner Gattin zuerst ihre Stockfischhaut, dann ihre Bären-, Gänse-, Hunde-, Hasen-, Ross-, Katzen- und schließlich ihre Schweinehaut herunter schlägt, bevor ihre Menschenhaut zum Vorschein kommt und sie sich ihm unterwirft. ${ }^{16}$ Nicht weniger brachiale Mittel gelangen in Unartigen Weiber Haupt Schmid zur Darstellung, wo die Unterwerfung eigensinniger Ehefrauen durch eine Werkstatt, in der deren Köpfe durch einen Schmied bearbeitet werden, versinnbildlicht wird. ${ }^{17}$

Der Topos der Mala mulier findet sich innerhalb der frühneuzeitlichen Bildpublizistik auch in weiteren Spielarten, so etwa im Motiv des sich von guten Ehemännern ernährenden, fetten Ungeheuers Bigorne und des sich von guten Ehefrauen ernährenden, abgemagerten Fabelwesens Cicheface ${ }^{18}$ oder in der an Obszönitäten reichen Erzählung über eine Frau im Elsass, die versucht, ihrem Mann die Geldtasche zu stehlen, um ihren liederlichen Lebenswandel zu finanzieren. ${ }^{19}$ Vor allem jedoch ist es der auch außerhalb Deutschlands vielfach belegte ,Kampf der Frauen um die Hosen', der als eingängige Bildformel für den weiblichen Machtanspruch fungiert. In Anlehnung an einen Vers aus dem Alten Testament (Jes 4,1) stellen gleich mehrere Flugblätter dar, wie sich sieben Frauen um die Hose eines Mannes bemühen. ${ }^{20}$ Der Kampf um die Hose steht dabei einerseits für weibliches Begehren,

\footnotetext{
${ }^{12}$ Harms/Schilling (wie Anm. 4), Nr. 152.

${ }^{13}$ Harms/Schilling (wie Anm. 4), Nr. 114. Vgl. in diesem Zusammenhang das kontrafaktisch zum genannten Druck angelegte Flugblatt Weiber Recept, das den Ehefrauen Gehorsam empfiehlt. Das Flugblatt ist abgedruckt in David Kunzle: History of the Comic Strip. Vol. 1: The Early Comic Strip. Narrative Strips and Picture Stories in the European Broadsheet from c. 1450 to 1825. Berkeley 1973, S. 235.

${ }^{14}$ Das Flugblatt ist abgedruckt in Kunzle (wie Anm. 13), S. 232f.

${ }^{15}$ Harms/Schilling (wie Anm. 4), Nr. 115.

${ }^{16}$ Deutsche illustrierte Flugblätter des 16. und 17. Jahrhunderts. Hrsg. von Wolfgang Harms. Band IV: Die Sammlungen der Hessischen Landes- und Hochschulbibliothek in Darmstadt. Kommentierte Ausgabe. Hrsg. von Wolfgang Harms und Cornelia Kemp. Tübingen 1987, Nr. 26.

${ }^{17}$ Harms/Schilling (wie Anm. 4), Nr. 113.

${ }^{18}$ Vgl. Harms/Schilling (wie Anm. 4), Nr. 108, sowie Deutsche illustrierte Flugblätter des 16. und 17. Jahrhunderts. Hrsg. von Wolfgang Harms. Band VII: Die Sammlung der Zentralbibliothek Zürich. Kommentierte Ausgabe. Teil 2: Die Wickiana II (1570-1588). Hrsg. von Wolfgang Harms und Michael Schilling. Tübingen 1987, Nr. 168. Vgl. auch Coupe (wie Anm. 8), Nr. 70.

${ }^{19}$ Vgl. Harms/Schilling (wie Anm. 4), Nr. 110. Vgl. auch Hofmann-Randall (wie Anm. 11), S. 55, A II 13.

${ }^{20}$ Vgl. beispielsweise Harms/Schilling (wie Anm. 4), Nr. 148, oder Harms/Kemp (wie Anm. 16), Nr. 25.

Weitere Fassungen des ,Kampfes um die Hosen' sind abgedruckt in Coupe (wie Anm. 8), Nr. 125, sowie in
} 
Erschienen in: Anthropologie und Medialität des Komischen im 17. Jahrhundert (1580-1730), S. 429-463, https://doi.org/10.1163/9789401205993 019, Leiden, Brill, 2015

für den Wunsch der Frauen nach männlicher Potenz, und pars pro toto nach dem Mann generell, und andererseits für deren Willen, sich das eheliche Gewaltmonopol anzueignen. Nicht zufällig werden die Kämpfenden denn auch wiederholt als ,böse Weiber' tituliert. ${ }^{21}$ Der großen Zahl von Darstellungen herrschsüchtiger Ehefrauen stehen nur wenige Einblattdrucke gegenüber, die das Beispiel einer guten Ehefrau vor Augen führen. Was Letztere ausmacht, ergibt sich ex negativo aus der satirischen Denunziation der schlechten Ehefrau und wird nur selten explizit erörtert. Immerhin werden im bereits erwähnten Flugblatt Von Einem Bößen Weib nicht nur die Unarten einer schlechten, sondern auch die Tugenden einer frommen Ehefrau konkretisiert, wenn es heißt: „Ein böß Weib macht Viel Hertzenleyd Ein fromme bringt Viel taußend frewd, Ein böß Weib regiert ihren Mann, Ein fromme ist ihm Vnterthan. Ein böß Weib treibt Viel tausendt Tuck, Ein fromme ist des Mannes gluck, Ein böß Weib macht einen gar verkehrt, Ein fromme ist aller Ehren Werth. “22 Noch ausführlicher äußert sich Spiegl dich Weib/Spiegl dich hierauß/Wie du solt fleissig halten Hauß zu den Merkmalen einer guten Ehegattin: Verschwiegenheit, das fleißige Verrichten der anfallenden Hausarbeit, die Erziehung der Kinder zur Gottesfurcht, Friedensliebe, Treue und Gehorsam dem Ehemann gegenüber werden als herausragende Eigenschaften einer frommen Ehefrau gerühmt, Eigenschaften, die ihr, so der Verfasser des Flugblatts, nicht nur die Liebe des Gatten, sondern auch gesellschaftliche Anerkennung sicherten. ${ }^{23}$

Angesichts der bemerkenswerten Häufung von Einblattdrucken, die die Boshaftigkeit der Ehefrauen thematisieren, drängt sich die Frage nach deren ,Sitz im Leben' auf. Wie lässt sich die überwiegend negative Darstellung der Ehe und insbesondere der Ehefrau in der frühneuzeitlichen Bildpublizistik erklären, inwiefern bilden die vorgängig benannten Flugblätter Konfliktfelder ab, die zu den zentralen lebensweltlichen Erfahrungen zeitgenössischer Leser gehörten? Zunächst gilt es zu beachten, dass die in den Einblattdrucken des 16. und 17. Jahrhunderts geläufigen Beschreibungsmuster für das Verhältnis der Geschlechter sich eher einer in die Antike zurückreichenden Diskursformation als geschichtlicher Realität verdanken. Sowohl in der griechisch-römischen Philosophie und Literatur als auch in der jüdisch-christlichen Überlieferung dominieren androzentrische und andronormative Konzepte den Diskurs über Wesen und Aufgabe der Frau. Bei so gut wie allen Autoren wird der weibliche Mensch als das Andere des Mannes bestimmt, wobei Letzterem in der Hierarchie der Geschlechter in der Regel die höhere Position zugewiesen wird. Das philosophisch, theologisch, medizinisch und juristisch begründete Postulat der Inferiorität der Frau bildet auch in Mittelalter und Früher Neuzeit den Angelpunkt des Geschlechterdiskurses. Zwar werden im Kontext der seit dem 15. Jahrhundert an Intensität gewinnenden Querelle des femmes alternative Positionen formuliert und der physische, moralische und intellektuelle Status der Frau neu verhandelt, ${ }^{24}$ dennoch bleibt die

Fuchs: Sittengeschichte (wie Anm. 6), S. 217, Nr. 191; S. 233, Nr. 206; Beilage zu S. 320, und Eduard Fuchs: Die Frau in der Karikatur. Erw. Neuausgabe. München 1928, S. 71, Nr. 62.

${ }^{21}$ So etwa in Harms/Schilling (wie Anm. 4), Nr. 148.

${ }^{22}$ Harms/Schilling (wie Anm. 4), Nr. 152.

${ }^{23}$ Vgl. Illustrierte Flugblätter des Barock. Eine Auswahl. Hrsg. von Wolfgang Harms, John Roger Paas, Michael Schilling, Andreas Wang. Tübingen 1983 (= Deutsche Neudrucke: Reihe Barock 30), Nr. 26.

${ }^{24}$ Aus der mittlerweile umfangreichen Forschungsliteratur zur frühneuzeitlichen Querelle des femmes sollen hier nur einige wenige, grundlegende Beiträge genannt werden: Katharina Fietze: Spiegel der Vernunft. Theorien vom Menschsein der Frau in der Anthropologie des 15. Jahrhunderts. Paderborn 1991; Claudia Opitz: Streit um Frauen? Die frühneuzeitliche Querelle des femmes aus sozial- und frauengeschichtlicher Sicht. In: Historische Mitteilungen 8 (1995), S. 15-27; Gisela Bock und Margarete Zimmermann: Die Querelle des Femmes in Europa. Eine begriffs- und forschungsgeschichtliche Einführung. In: Querelles. Jahrbuch für Frauenforschung 1997. Bd. 2: Die europäische Querelle des Femmes. Geschlechterdebatten seit dem 15. Jahrhundert. Hrsg. von Gisela Bock und Margarete Zimmermann. Stuttgart 1997, S. 9-38; Friederike Hassauer: Der Streit um die Frauen. Elf Fragen und Antworten. In: Geschlechterperspektiven. Forschungen zur Frühen Neuzeit. Hrsg. von Heide Wunder und Gisela Engel. Königstein/Ts. 1998, S. 255-261; Andrea Maihofer: Die Querelle des femmes: Lediglich 
Erschienen in: Anthropologie und Medialität des Komischen im 17. Jahrhundert (1580-1730), S. 429-463, https://doi.org/10.1163/9789401205993 019, Leiden, Brill, 2015

Leitvorstellung vom Primat des Mannes im wesentlichen unangefochten und bildet in der Folge das ideelle Kristallisationszentrum all jener zunehmend zahlreichen Textkorpora, die sich mit der Institution der Ehe befassen. Neben Sentenzen- bzw. Bibelkommentaren und theologischen sowie Bußsummen sind es vor allem die Ehe- und Ökonomietraktate sowie Predigten und hier insbesondere die Hochzeitspredigten, in denen die Ehe einen zentralen Platz einnimmt. Nicht weniger wirkungsmächtig als die genannten normativen Quellen dürften mit Blick auf die Auffassung der Ehe und die damit verbundenen Geschlechterkonstruktionen außerdem enzyklopädische Werke, Exempelsammlungen, Emblembücher sowie die vielfältigen künstlerischen und literarischen Artefakte, die sich den nicht nur ehelichen Beziehungen zwischen Mann und Frau widmen, gewesen sein. Von besonderer Signifikanz sind in unserem Zusammenhang jene literarischen Genres, in denen die in Flugblättern des 16. und 17. Jahrhunderts bezeugten misogynen und misogamen Topoi zum Gattungsinventar gehören. Dies gilt in erster Linie für die Schwankdichtung ${ }^{25}$, für die sich an Vorlagen aus der Romania orientierende Novellenliteratur oder für das Fasnachtsspiel $^{26}$, die das Motiv des ,bösen Weibes' variantenreich gestalten.

Es ist der Blick auf die hier nur angedeuteten Traditionslinien, der deutlich macht, wie viel gerade die satirischen Einblattdrucke ihren - nicht nur - literarischen Vorbildern verdanken. ${ }^{27}$ So finden sich auf Flugblättern nicht nur motivische Anleihen, sondern auch wörtliche Zitate aus Schwänken und Fasnachtsspielen von Hans Sachs ${ }^{28}$ und der auch auf mittelalterlichen Misericordien dargestellte, ${ }^{29}$ in Einblattdrucken wiederholt ins Bild gesetzte ,Kampf um die Hose' lässt sich auf ein französisches Fabliau zurückführen. ${ }^{30}$ Aus den offenkundigen intertextuellen Bezügen zwischen Bildpublizistik und den vorgängig genannten Gattungen zu schließen, bei der auf frühneuzeitlichen Einblattdrucken überlieferten Ehesatire handle es sich um ein rein literarisches Phänomen, greift nun allerdings zu kurz. So wenig es sich bei den die Institution Ehe thematisierenden Flugblättern um eine Abbildung realer Verhältnisse handelt, so wenig stellen diese nur eine weitere Spielart eines durch die Dichtung vorgegebenen Musters dar. Die Einsicht in die Traditionsgebundenheit der in Zusammenhang mit der Darstellung ehelicher Beziehungen in frühneuzeitlicher Bildpublizistik begegnenden Topoi

literarisches Genre oder spezifische Form der gesellschaftlichen Auseinandersetzung um Wesen und Status der Geschlechter? In: Geschlechterperspektiven. Forschungen zur Frühen Neuzeit (a.a.O.), S. 262-272;

Geschlechterstreit am Beginn der europäischen Moderne. Die Querelle des femmes. Hrsg. von Gisela Engel, Friederike Hassauer, Brita Rang und Heide Wunder. Königstein/Ts. 2004 (= Kulturwissenschaftliche Gender Studies 6).

${ }^{25}$ Vgl. etwa Monika Jonas: Idealisierung und Dämonisierung als Mittel der Repression. Eine Untersuchung zur Weiblichkeitsdarstellung im spätmittelalterlichen Schwank. In: Der Widerspenstigen Zähmung. Studien zur bezwungenen Weiblichkeit in der Literatur vom Mittelalter bis zur Gegenwart. Hrsg. von Sylvia Wallinger und Monika Jonas. Innsbruck 1986 (= Innsbrucker Beiträge zur Kulturwissenschaft. Germanistische Reihe 31), S. 67-93.

${ }^{26}$ Vgl. Elisabeth Keller: Die Darstellung der Frau in Fastnachtspiel und Spruchdichtung von Hans Rosenplüt und Hans Folz. Frankfurt/M. 1992 (= Europäische Hochschulschriften I 1325).

${ }^{27}$ Zur mittelalterlichen ikonographischen Tradition des ehelichen Geschlechterkampfs vgl. Malcolm Jones: The Secret Middle Ages. Phoenix Mill 2002, S. 226-247.

${ }^{28}$ So handelt es sich bei Kurtze Beschreibung Der neunh(utigen Weiber um eine Adaption eines Schwanks von Hans Sachs (vgl. Hans Sachs: Sämtliche Fabeln und Schwänke. Hrsg. von Edmund Goetze und Carl Drescher. Bd. 1. Halle a. d. Saale 1893 (= Neudrucke deutscher Litteraturwerke des XVI. und XVII. Jahrhunderts 110117), S. 164-169) und der scherzhafte Dialog zwischen einem jungen Mann, der einer Magd seine Liebe gesteht und abgewiesen wird, und seiner Angebeteten in Hiebey kann man abnehmen frey/ Wie es pflegt zu gehen auff L=ffeley (Harms/Schilling (wie Anm. 4), Nr. 94) ist Sachs' Fastnachtspiel Von einem bösen weib entnommen (Hans Sachs: Sämmtliche Fastnachtspiele. Bd. 1: Zwölf Fastnachtspiele aus den Jahren 1518-1539. Hrsg. von Edmund Goetze. Halle a. d. Saale 1880 (= Neudrucke deutscher Litteraturwerke des XVI. und XVII. Jahrhunderts 26/27), Nr. 4, S. 36-53).

${ }^{29}$ Vgl. Christa Grössinger: Picturing Women in Late Medieval and Renaissance Art. Manchester 1997, S. 116ff. ${ }^{30}$ Vgl. Lutz Röhrich: Das große Lexikon der sprichwörtlichen Redensarten. Bd. 2. Freiburg/Br. 1992, S. 748. 
Erschienen in: Anthropologie und Medialität des Komischen im 17. Jahrhundert (1580-1730), S. 429-463, https://doi.org/10.1163/9789401205993 019, Leiden, Brill, 2015

erklärt noch nicht deren außerordentliche Beliebtheit im 16. und 17. Jahrhundert. Immerhin hielt der Fundus an Überlieferung auch einen reichhaltigen philogynen Strang bereit, der sich in Anthologien berühmter Frauen, in Traktaten, welche die gegen Frauen gerichteten Schmähschriften für gegenstandslos erklärten oder in in der Tradition des Minnesangs stehenden lyrischen Werken konkretisierte. Wenn die Frage, weshalb die Verfasser und Herausgeber von Flugblättern aus der heterogenen antiken, mittelalterlichen und humanistischen Literatur zum Verhältnis zwischen Mann und Frau primär misogyne Topoi aktualisierten, einer Antwort zugeführt werden soll, bedarf es demnach einer Funktionsanalyse, die den konfessions-, sozial- und rechtsgeschichtlichen Hintergrund, vor dem die Auseinandersetzung mit der Ehe sich im hier interessierenden Zeitraum vollzieht, nicht ausblendet.

Die seit dem späten 15. Jahrhundert immer zahlreicher gedruckten Eheschriften machen deutlich, in welchem Maße die Ehe im Übergang zur Vormoderne an Relevanz gewinnt. Dass die eheliche Gemeinschaft von Mann und Frau in den Fokus frühneuzeitlicher Autoren gerät, hängt mit einer Reihe von religiösen, sozioökonomischen und juristischen Entwicklungen zusammen, die im Folgenden knapp skizziert werden sollen: Der relativ hohe Anteil Unverheirateter, die Zunahme klandestiner Eheschließungen sowie das unter katholischen Priestern weit verbreitete Konkubinat um 1500 lassen sich als Indikatoren für eine Strukturkrise der Ehe werten, auf die die Reformatoren, allen voran Martin Luther, früh reagierten. ${ }^{31}$ Nachdem der Wittenberger Professor bereits 1519 seinen Sermon vom ehelichen Stand veröffentlicht hatte, entwickelt er auf dem Fundament der in den 1520 erschienenen reformatorischen Hauptschriften dargelegten theologischen Postulate eine Eheprogrammatik, die in Vom ehelichen Leben (1522) ihre prägnanteste Ausformulierung erfährt. Die worttheologische Neubegründung der Ehe durch Luther stellt nicht nur deren sakramentalen Charakter in Frage, erteilt dem Ideal monastischer Weltflucht und dem Priesterzölibat eine Absage und unterzieht die katholischen Ehevollzugsnormen einer grundlegenden Revision, sie beinhaltet zugleich eine veränderte Bestimmung der religiösen und vor allem sozialen Funktion der Ehe. Anders als die katholische Tradition mit ihrer Privilegierung der Ehelosigkeit wertet das lutherische Eheverständnis Ehe und Familie in signifikanter Weise auf, indem es sie zur maßgeblichen Lebensform erhebt. Die reformatorische Neubestimmung der Ehe wirkt sich nicht nur auf deren theologischen Status aus, sondern zeitigt darüber hinaus Folgen für deren gesellschaftliche Funktion. Sie erscheint nun als jener Modus sozialer Interaktion, der die politische Ordnung antizipiert und stabilisiert und bildet zugleich die Keimzelle ökonomischen Wohlstands. Dies hat Konsequenzen für die Stellung der Frau innerhalb der Familie. Zwar bleibt auch das lutherische Eheverständnis einer andronormativen Argumentationslogik verhaftet und hält an der anthropologisch begründeten hierarchischen Geschlechterordnung fest, der Ehefrau als Herrin des Hauses werden jedoch weitgehende Befugnisse in der Organisation der häuslichen Ökonomie zugestanden. Indem sie außerdem für die Erziehung der Kinder und die Kontrolle über das Gesinde zuständig ist, trägt sie eine hohe ethische Verantwortung, die sich auch auf ihren Ehemann erstrecken kann. Nicht zufällig vertreten nicht nur die meisten lutherischen Ehetraktate, sondern auch und vor allem die zahlreich überlieferten Hochzeitspredigten protestantischer Provenienz tendenziell philogyne Positionen, grenzen sich von den antiken und mittelalterlichen misogynen Auffassungen $a b$ und heben im Rekurs auf die jüdische Weisheitsliteratur den Wert einer

\footnotetext{
${ }^{31} \mathrm{Zu}$ den folgenden Ausführungen vgl. Joel F. Harrington: Recordering Marriage and Society in Reformation Germany. Cambridge 1995; Barbara Henze: Kontinuität und Wandel des Eheverständnisses im Gefolge von Reformation und katholischer Reform. In: „In Christo ist weder man noch weyb“. Frauen in der Zeit der Reformation und katholischen Reform. Hrsg. von Anne Conrad. Münster 1999 (Katholisches Leben und Kirchenreform im Zeitalter der Glaubensspaltung 59), S. 129-151 sowie v.a. Margraf (wie Anm. 1 [dort weitere Literatur]).
} 
Erschienen in: Anthropologie und Medialität des Komischen im 17. Jahrhundert (1580-1730), S. 429-463, https://doi.org/10.1163/9789401205993 019, Leiden, Brill, 2015

tugendhaften und frommen Hausfrau hervor. Zugleich findet die bereits im mittelalterlichen Ehediskurs einsetzende Aufwertung der affektiven Liebe in den protestantischen Eheschriften eine Fortsetzung. ${ }^{32}$ Das Verhältnis zwischen den Ehegatten erfährt eine zunehmende Spiritualisierung; die Ehe erscheint nicht nur als Abbild und Garant gesellschaftlicher Ordnung, sondern auch als Analogon des Verhältnisses zwischen Christus und der Kirche. Indem nun die protestantischen Theologen den männlichen Ehegatten im Rahmen eines auf Komplementarität zielenden Geschlechtermodells auf einen biblisch präfigurierten ,Liebespatriarchalismus' verpflichten, wird das Gewaltmonopol des Mannes in Ehe und Familie relativiert.

Der Wandel, welchen die Auffassung von der Ordnung der Geschlechter innerhalb der Ehe im 16. und 17. Jahrhundert erfährt, ist allerdings nicht allein theologisch begründet. Die bereits im Hochmittelalter einsetzenden weit reichenden Strukturveränderungen in der

Agrarwirtschaft und die Entwicklungen in Handwerk und Handel, die mit der Herausbildung einer frühkapitalistischen Ökonomie einhergehen, bleiben nicht ohne Einfluss auf die Rolle der Frau. Angesichts der Vielfalt weiblicher Lebensentwürfe, angesichts der sich ständisch, konfessionell, regional ausdifferenzierenden Handlungsspielräume von Frauen, ist Vorsicht geboten, wenn es darum geht, den sozialen und ökonomischen Ort - genauer die sozialen und ökonomischen Orte - von Frauen in der Frühen Neuzeit zu bestimmen. ${ }^{33}$ Dennoch ist es möglich, zumindest Tendenzen zu beschreiben, die sich auch oder sogar in erster Linie auf den Status von Frauen innerhalb der ehelichen Gemeinschaft auswirkten. Die Frau trägt zwar weiterhin in entscheidender Weise zur Existenzsicherung bei, im Zuge einer zunehmenden, auf die Professionalisierung der Produktionsweise zielenden Arbeitsteilung werden die dem Mann bzw. der Frau zugewiesenen Aufgabenfelder jedoch stärker geschlechtsspezifisch definiert. Vor allem im städtischen Kontext ist es nun primär der Bereich des Hauses, für den die Frau die Verantwortung trägt. Darüber, dass der frühneuzeitliche Haushalt weit mehr umfassen konnte als die aus Eltern und Kindern bestehende Kernfamilie und dass Haushalt und beruflicher Tätigkeitsbereich des Mannes nicht selten interferierten, besteht in der historischen Forschung Konsens. So hatten beispielsweise Ehefrauen von Handwerkern oder Kaufleuten bisweilen erheblichen Anteil am ökonomischen Erfolg ihres Gatten, was allerdings nicht verhindert hat, dass als genuine Wirkungsstätte der Frau in zunehmendem Maße das Haus galt. Die dadurch erfolgte ,Einhegung' wurde immerhin dadurch kompensiert, dass eine Hausfrau, zumindest innerhalb des ihr zugestandenen Aufgabenbereichs, über relativ große Autonomie verfügte. Zwar blieb sie theoretisch auch als Hausherrin dem Dominat ihres Ehemannes unterstellt, die praktischen Anforderungen häuslicher Wirtschaft waren jedoch ohne ein gewisses Maß an Handlungsbefugnis nicht zu bewältigen. ${ }^{34}$ Die

\footnotetext{
${ }^{32}$ Vgl. dazu Rüdiger Schnell: Liebesdiskurs und Ehediskurs im 15. und 16. Jahrhundert. In: The Graph of Sex and the German Text. Gendered Culture in Early Modern Germany 1500-1700. Hrsg. von Lynne Tatlock. Amsterdam 1994 (= Chloe. Beihefte zum Daphnis 19), S. 79-120; Hans-Georg Kemper: Hölle und „Himmel auf der Erden“: Liebes-, Hochzeits- und Ehelyrik in der frühen Neuzeit. In: Mittelalter und frühe Neuzeit. Übergänge, Umbrüche und Neuansätze. Hrsg. von Walter Haug. Tübingen 1999, S. 30-77, sowie v.a. Rüdiger Schnell: Sexualität und Emotionalität in der vormodernen Ehe. Köln 2002 und Arndt Weber: Affektive Liebe als „rechte eheliche Liebe“ in der ehedidaktischen Literatur der frühen Neuzeit. Eine Studie unter besonderer Berücksichtigung der Exempla zum locus Amor coniugalis. Frankfurt/M. 2001 (= Europäische Hochschulschriften I, 1819).

${ }^{33}$ Zur Stellung der Frau in der Frühen Neuzeit vgl. die Überblickswerke von Heide Wunder: „Er ist die Sonn', sie ist der Mond“. Frauen in der Frühen Neuzeit. München 1992; Geschichte der Frauen. Bd. 3: Frühe Neuzeit. Hrsg. von Arlette Farge und Natalie Zemon Davies. Frankfurt/M. 1994, sowie Olwen Hufton: Frauenleben. Eine europäische Geschichte 1500-1800. Frankfurt/M. 1995. Vgl. auch Barbara Becker-Cantarino: Der lange Weg zur Mündigkeit. Frau und Literatur (1500-1800). Stuttgart 1987, S. 19-58, sowie Paul Münch: Lebensformen in der frühen Neuzeit. Frankfurt/M. und Berlin 1992, S. 191-232.

${ }^{34}$ Vgl. dazu beispielsweise Irmintraut Richarz: Oeconomia: Lehren vom Haushalten und Geschlechterperspektiven. In: Wunder/Engel (wie Anm. 24), S. 316-336.
} 
Erschienen in: Anthropologie und Medialität des Komischen im 17. Jahrhundert (1580-1730), S. 429-463, https://doi.org/10.1163/9789401205993 019, Leiden, Brill, 2015

Lebenssituation insbesondere bürgerlicher Ehefrauen war demnach seit dem 16. Jahrhundert durch eine konfliktträchtige Ambivalenz gekennzeichnet: Im gesellschaftlichen Diskurs wurden sie auf ihre Gehorsamspflicht dem Ehemann gegenüber verwiesen, in ihrer alläglichen Erfahrungswelt hingegen sahen sie sich mit der Notwendigkeit konfrontiert, weit reichende Entscheidungen, welche die Gesamtheit der in dem von ihnen geführten Haushalt lebenden Personen betrafen, zu verantworten. Wenn in frühneuzeitlicher Bildpublizistik mit auffallender Häufigkeit die Bewegungsfreiheit der Ehefrau, das Trinkverhalten des Ehemannes oder die sich aus dem Umgang mit den finanziellen Ressourcen der Familie ergebenden Konflikte thematisiert werden, hängt dies nicht zuletzt mit der hier angedeuteten Überlappung der Frauen und Männern zugeordneten Verantwortungsbereiche zusammen. Parallel zu den konfessions- und sozialgeschichtlich bedingten Veränderungen des Status' verheirateter Frauen wurde im 16. und 17. Jahrhundert auch deren rechtliche Stellung verbessert. ${ }^{35}$ Nachdem es bereits im späten Mittelalter Bestrebungen gegeben hatte, die Rechtssicherheit von Ehefrauen zu erhöhen, erfuhren die die Ehe betreffenden rechtlichen Normen seit dem 16. Jahrhundert eine grundlegende Erweiterung und Präzisierung. Dies hängt nicht zuletzt damit zusammen, dass im Gefolge der Reformation die Ehe, zumindest in protestantischen Gebieten, nicht mehr Sache der Kirche, sondern staatliche Angelegenheit war und die Obrigkeiten der Reichsterritorien sich vor die Aufgabe gestellt sahen, Gesetze zu erlassen sowie Institutionen zur Umsetzung und Kontrolle ebendieser Gesetze zu schaffen, die geeignet waren, auf Konflikte, die sich in Zusammenhang mit Eheschließung und Ehescheidung ergaben, adäquat zu reagieren. Auch wenn dies selten explizit formuliert wird, gilt im Bereich des frühneuzeitlichen Eherechts weiterhin das Prinzip vir est caput mulieris. Immerhin verband sich mit der Eheschließung nicht nur für die Frau, sondern auch für den Mann eine Reihe von Pflichten, die vor Gericht einklagbar waren. Besondere Bedeutung erlangten in diesem Zusammenhang die im 16. Jahrhundert neu geschaffenen Sitten- und Ehegerichte, an die sich verheiratete Personen beiderlei Geschlechts wenden konnten, wenn es innerhalb der Ehe zu Verstößen gegen geltendes Recht gekommen war. ${ }^{36}$ Die Tatsache, dass es in erster Linie Frauen waren, die vor den Sitten- und Ehegerichten als Klägerinnen auftraten, darf als Indiz für den größeren juristischen Spielraum gewertet werden, über den Ehefrauen verfügten, um sich gegen ungesetzliche Praktiken ihres Mannes zu wehren. Die in protestantischen Territorien mit Ehesachen befassten Sitten- und Ehegerichte sind nicht nur ein Indikator für die verbesserte Rechtsstellung verheirateter Frauen, sie offenbaren darüber hinaus, welche Bedeutung der frühneuzeitliche Staat der Lebensgemeinschaft von Mann und Frau beimaß. Gemäß der Maxime, dass die auf die Autorität des pater familias gegründeten Herrschaftsbeziehungen zu Ehefrau, Kindern und Gesinde in der Organisation des Staates und insbesondere im Verhältnis zwischen Obrigkeit und Untertanen ihre Entsprechung fänden, kam der Ehe eine gewissermaßen , staatstragende' Funktion zu. ${ }^{37}$ Das Haus stellte keinen privaten Ort dar, sondern war als zentraler Bestandteil der ,guten Policey' ${ }^{38}$ in die öffentliche Sphäre eingebunden und unterstand damit der Kontrolle des Staates. Verstöße gegen die

\footnotetext{
${ }^{35}$ Vgl. dazu Hartwig Dieterich: Das protestantische Eherecht in Deutschland bis zur Mitte des 17. Jahrhunderts. München 1970 (= Jus Ecclesiasticum Bd. 10).

${ }^{36}$ Zur frühneuzeitlichen Ehegerichtsbarkeit vgl. exemplarisch die Fallstudie von Roland E. Hofer: „Üppiges, unzüchtiges Lebwesen“. Schaffhauser Ehegerichtsbarkeit von der Reformation bis zum Ende des Ancien Régime (1529-1798). Bern 1993 (= Geist und Werk der Zeiten 82).

${ }^{37}$ Zum Vorbildcharakter der Ehe für die politische Organisation menschlichen Zusammenlebens vgl. Elisabeth Koch: Major dignitas est in sexu virili. Das weibliche Geschlecht im Normensystem des 16. Jahrhunderts. Frankfurt/M. 1991 (= Ius Commune 57), S. 191-197.

${ }^{38}$ Zu Begriff und Phänomen ,Policey’ vgl. Michael Stolleis: Policey im Europa der Frühen Neuzeit. Frankfurt/M. 1996 (= Ius Commune. Sonderhefte 83) sowie den Forschungsbericht von Andreas Hieber: Policey zwischen Augsburg und Zürich - ein Forschungsüberblick. In: Gute Policey als Politik im 16. Jahrhundert. Die Entstehung des öffentlichen Raumes in Oberdeutschland. Frankfurt/M. 2003 (= Studien zu Policey und Policeywissenschaft [keine Bandnummer!]), S. 1-24.
} 
Erschienen in: Anthropologie und Medialität des Komischen im 17. Jahrhundert (1580-1730), S. 429-463, https://doi.org/10.1163/9789401205993 019, Leiden, Brill, 2015

gesetzlich sanktionierten ehelichen Normen bedeuteten im Verständnis nicht weniger Juristen und Staatstheoretiker des 16. und 17. Jahrhunderts denn auch eine potentielle Gefahr für die öffentliche Ordnung und wurden deshalb auch dann geahndet, wenn es sich beim Beklagten um einen Mann handelte.

Es gehört zu den Verdiensten der historischen Geschlechterforschung, deutlich gemacht zu haben, wie heterogen, ja bisweilen widersprüchlich sich die Realität von Frauen in der Frühen Neuzeit gestaltete. Im Modus einer naturgemäß vereinfachenden Darstellung wichtiger Tendenzen ist die komplexe Vielfalt weiblicher Erfahrungswelten nicht adäquat zu erfassen. Konstitutiv für die ständisch gegliederten und konfessionell ausdifferenzierten Gesellschaften des 16. und 17. Jahrhunderts ist nicht nur das Nebeneinander unterschiedlicher Lebensentwürfe von Frauen, sondern - auch darauf haben Forscherinnen und Forscher hingewiesen - außerdem die Diskrepanz zwischen Geschlechternorm und alltäglicher Praxis. Die überlieferten Quellen vermitteln nicht unbedingt ein verlässliches Bild wirklicher Verhältnisse; sie dokumentieren die moraltheologischen und ordnungspolitischen Auffassungen der Funktionseliten, nicht jedoch die Denk- und Handlungsweisen breiterer Bevölkerungsschichten. Sie tun dies überdies nicht selten auf eine Art und Weise, die deren Verankerung in spezifischen diskursiven und literarischen Traditionen offenkundig erscheinen lässt. Dies gilt auch und gerade für die vorgängig erörterten Einblattdrucke, wie der nochmalige Blick auf den Topos des ,bösen Weibs' auf exemplarische Weise erhellt: Dass es zwischen Ehegatten immer wieder zu Konflikten gekommen ist, belegen die uns erhaltenen Visitationsprotokolle und Prozessakten, die sich mit Verstößen gegen die Ehe betreffende Normen befassen. Sie zeichnen allerdings ein durchaus anderes Bild als all jene Flugblätter, die in der Bosheit und Liederlichkeit der Frau die Ursache für eheliche Krisen erkennen. Es sind in der Regel nicht die Frauen, sondern vielmehr die Männer, die durch gewohnheitsmäßiges Trinken, durch einen die Familie belastenden Umgang mit Geld, durch Ehebruch oder durch exzessive Gewaltanwendung den Ehefrieden bedrohen. ${ }^{39}$ Auch in Kanzelreden aus dem 17. Jahrhundert beklagen die Prediger wiederholt den übermäßigen Alkoholkonsum, die Spielsucht und den ehebrecherischen Lebenswandel von Ehemännern und die sich daraus ergebenden Konsequenzen für die Familie und zeigen Verständnis dafür, wenn die Ehefrau unter derartigen Bedingungen ihren Haushalt verteidigt. ${ }^{40}$ Vorsicht ist auch im Umgang mit den zahlreich gedruckten Prügelrezepten für ungehorsame Ehefrauen geboten. Zwar galt das bereits im Mittelalter verbriefte Züchtigungsrecht des Mannes in Deutschland noch bis weit ins 19. Jahrhundert hinein; es war jedoch expliziten Beschränkungen unterworfen. ${ }^{41}$ Die Frau ist, darüber besteht unter den Juristen des 16. und 17. Jahrhundert weitgehend Konsens, nicht verpflichtet, die körperliche Misshandlung durch den Ehegatten zu erdulden. Im Falle über ein angemessenes Maß hinaus gehender Grausamkeit oder wenn es gar zu schwerwiegenden Verletzungen kommt - der rechtliche Terminus lautet in diesem Fall saevitia - kann von den Gerichten eine Trennung der Ehegatten ausgesprochen werden. ${ }^{42}$ Bei der Entscheidung darüber, wann ein Mann die Grenzen des ihm zugestandenen Züchtigungsrechts überschritten hatte, verfügten die Richter

\footnotetext{
${ }^{39}$ Vgl. etwa Claudia Ulbrich: Unartige Weiber. Präsenz und Renitenz von Frauen im frühneuzeitlichen Deutschland. In: Arbeit, Frömmigkeit und Eigennutz. Hrsg. von Richard van Dülmen. Frankfurt/M. 1990, S. 1342 und 300-304, hier S. 40, oder Siegrid Westphal: Kirchenzucht als Ehe- und Sittenzucht. Die Auswirkungen von lutherischer Konfessionalisierung auf das Geschlechterverhältnis. In: Conrad (wie Anm. 31), S. 152-171, hier S. 166 und 168. Zu männlicher Gewaltanwendung innerhalb der Ehe vgl. außerdem Hofer (wie Anm. 36), S. 320-325.

${ }^{40}$ Vgl. Elfriede Moser-Rath: Familienleben im Spiegel der Barockpredigt. In: Daphnis 10 (1981), S. 47-65, hier S. 56 und 59.

${ }^{41}$ Barbara Becker-Cantarino: Die böse Frau und das Züchtigungsrecht des Hausvaters in der frühen Neuzeit. In: Wallinger/Jonas (wie Anm. 25), S. 117-132.

${ }^{42}$ Vgl. Koch (wie Anm. 37), S. 38ff.
} 
Erschienen in: Anthropologie und Medialität des Komischen im 17. Jahrhundert (1580-1730), S. 429-463, https://doi.org/10.1163/9789401205993 019, Leiden, Brill, 2015

allerdings über erhebliche Ermessensspielräume; die entsprechende Jurisdiktion erweist sich denn auch als recht uneinheitlich. ${ }^{43}$ Nicht toleriert wurde die Tötung der Ehefrau; die von einigen Flugblättern empfohlenen Prügelrezepte mit letalem Ausgang stehen deshalb in krassem Widerspruch sowohl zur Rechtstheorie als auch zur Rechtspraxis der Frühen Neuzeit. Damit sind wir zum Ausgangspunkt unserer Überlegungen zurückgekehrt: Wie lässt sich, so lautete die Frage, die überwiegend negative Darstellung der Ehe und insbesondere der Ehefrau in der frühneuzeitlichen Bildpublizistik erklären und wie verhalten sich die Darstellungen ehelicher Beziehungen in Flugblättern zur zeitgenössischen Erfahrungswirklichkeit von Männern und Frauen? Es dürfte deutlich geworden sein, dass die eingangs beschriebenen Einblattdrucke nicht als Abbild realer Verhältnisse gedeutet werden dürfen. Zwar sind die Auswirkungen der Reformation und der katholischen Gegenreform auf die Geschlechterordnung in der historischen Forschung umstritten; der eheliche Status von Mann und Frau wird jedoch im Zuge der nicht nur konfessionellen Umwälzungen seit dem 16. Jahrhundert sowohl in theologischer, als auch in sozioökonomischer und juristischer Hinsicht einer grundlegenden Revision unterzogen und dies durchaus im Sinne des weiblichen Ehegatten. Nicht von ungefähr dominieren im Forschungsdiskurs denn auch jene Erklärungsmuster, die in den im 16. und 17. Jahrhundert zahlreich gedruckten misogynen und misogamen literarischen und publizistischen Manifestationen ein Indiz für die durch die Besserstellung der Frau ausgelösten Irritationen erkennen. Das Motiv des ,bösen Weibs' als Inkarnation weiblicher Herrschsucht verweist in dieser Lesart auf die den verheirateten Frauen neu eröffneten Handlungsoptionen und die dadurch bewirkte Verkehrung gottgewollter Ordnungen. Es erscheint so gesehen nur konsequent, wenn weiblicher Eigensinn und die daraus resultierende Inversion der Geschlechterhierarchie zum Topos der , Verkehrten Welt' in Beziehung gesetzt werden. ${ }^{44}$ Die hyperbolische Inszenierung einer aus den Fugen geratenen ehelichen Welt geschieht dann mit der Intention, vor den Konsequenzen einer Verletzung natürlicher Gesetze zu warnen und die bedrohte Ordnung der Geschlechter $\mathrm{zu}$ restituieren. ${ }^{45}$

Dass die Funktion der publizistisch dokumentierten Ehesatire wesentlich eine moraldidaktische ist, soll hier nicht bestritten werden. Die auf frühneuzeitlichen Einblattdrucken thematisierten Konflikte zwischen Ehegatten stehen in Widerspruch zur theologisch und rechtlich begründeten Norm einer harmonischen, auf Subsidiarität bzw. Komplementarität ausgerichteten Lebensgemeinschaft von Mann und Frau und stehen deshalb für eine zu vermeidende Form ehelicher Interaktion. ${ }^{46}$ Zudem leuchtet ein, dass in einem Moment, in dem die großen Konfessionskirchen neuartige Kontrollinstrumente schaffen, um ihre dogmatische Autorität zu sichern, und der sich modernisierende Staat Institutionen entwickelt, die sein Machtmonopol garantieren sollen, Ordnungsverstöße sanktioniert werden müssen. Sowohl das Konfessionalisierungs- als auch das Sozialdisziplinierungsparadigma

\footnotetext{
${ }^{43}$ Vgl. Dieterich (wie Anm. 35), S. 234-245, sowie Lyndal Roper: Das fromme Haus. Frauen und Moral in der Reformation. Aus dem Englischen von Wolfgang Kaiser. Frankfurt/M. 1995, S. 160-168.

${ }^{44}$ Vgl. dazu etwa Sara F. Matthews Grieco: Pedagogical Prints: Moralizing Broadsheets and Wayward Women in Counter Reformation Italy. In: Picturing Women in Renaissance and Baroque Italy. Hrsg. von Geraldine A. Johnson und Sara F. Matthews Grieco. Cambridge 1997, S. 61-87 und S. 261-269.

${ }^{45}$ Vgl. etwa Michael Schilling: Das Flugblatt als Instrument gesellschaftlicher Anpassung. In: Literatur und Volk im 17. Jahrhundert. Probleme populärer Kultur in Deutschland. Hrsg. von Wolfgang Brückner, Peter Blickle und Dieter Breuer. Wiesbaden 1985 (= Wolfenbütteler Arbeiten zur Barockforschung 13), S. 601-626, oder Ders.: Bildpublizistik in der frühen Neuzeit. Aufgaben und Leistungen des illustrierten Flugblatts in Deutschland bis um 1700. Tübingen 1990 (= Studien und Texte zur Sozialgeschichte der Literatur 29), S. 214231.

${ }^{46} \mathrm{Zu}$,Subsidiarität' bzw. ,Komplementarität' als dominierende Modelle ehelicher Beziehungen in den normativen Eheschriften der Frühen Neuzeit vgl. Maria E. Müller: Naturwesen Mann. Zur Dialektik von Herrschaft und Knechtschaft in Ehelehren der Frühen Neuzeit. In: Wandel der Geschlechterbeziehungen zu Beginn der Neuzeit. Hrsg. von Heide Wunder und Christina Vanja. Frankfurt/M. 1991, S. 43-68.
} 
Erschienen in: Anthropologie und Medialität des Komischen im 17. Jahrhundert (1580-1730), S. 429-463, https://doi.org/10.1163/9789401205993 019, Leiden, Brill, 2015

sind allerdings in jüngerer Zeit in die Kritik geraten und dies nicht ohne Grund. ${ }^{47}$ Manuel Braun beispielsweise hat kürzlich überzeugend dargelegt, dass das Leitparadigma der Disziplinierung nur sehr bedingt geeignet ist, die Leistung der den frühneuzeitlichen Ehediskurs konstitutierenden textuellen Äußerungen zu beschreiben. Zwar räumt auch Braun ein, dass der Ehediskurs im 16. Jahrhundert hinsichtlich seiner Intentionalität mit dem Begriff der ,Disziplinierung' zutreffend charakterisiert werden kann; ständisch geprägtes Denken und soziale Realität standen einer Erreichung der moraldidaktischen und disziplinierenden Absicht jedoch genau so entgegen, wie die spezifische Textualität der Eheschriften, die deren normativen Impetus unterminierte. ${ }^{48}$ Es sind insbesondere die „Überschüsse, die das metaphorische Sprechen entbindet““ ${ }^{49}$ und das „Paradox, dass Verbote dem sexuellen Begehren Stimme verleihen "50, die Anlass zur Vorsicht bieten. Angesichts der in der Forschung mit bemerkenswerter Konsequenz ignorierten kommerziellen Dimension frühneuzeitlicher Publizistik stellt sich außerdem die Frage, ob der zu erwartende moralische Nutzen die Leser zum Kauf veranlasste, oder ob es nicht vielmehr der offenkundige Unterhaltungswert satirischer Einblattdrucke war, der den primären Reiz derartiger Artefakte ausmachte..$^{51}$ Eine Funktionsbestimmung, welche die Literarizität und den satirischen Charakter der hier interessierenden Publizistik ausblendet, und deren Wirkung auf Moraldidaxe und Disziplinierung reduziert, wird - so das Fazit - den die Ehe thematisierenden Einblattdrucken nicht gerecht. Es fragt sich allerdings, ob nicht auch eine die Unterhaltungsabsicht privilegierende Deutung zu kurz greift und ob die publizistisch bewerkstelligte Ehesatire insbesondere im 17. Jahrhundert Funktionsmöglichkeiten birgt, die über das horazische prodesse aut delectare hinausgehen.

Erhellung verspricht in diesem Zusammenhang die Auseinandersetzung mit jenem literarischen Verfahren, auf das so gut wie alle Verfasser von Einblattdrucken zum Thema ,Ehe' zurückgegriffen haben - der Satire. Der Begriff, Satire' bezeichnet zum einen ein seit der Antike zum Formenbestand der europäischen Literaturen gehöriges Genre und zum anderen, gattungsübergreifend, eine Schreibweise, die durch ihre Personen oder Verhaltensund Denkmuster angreifende, die Wirklichkeit im Modus der Negativität darstellende Qualität gekennzeichnet ist. ${ }^{52}$ War die ältere Forschung - durchaus in Einklang mit dem

frühneuzeitlichen Satireverständnis ${ }^{53}$ - in der Regel davon ausgegangen, dass die Satire, wenn auch in indirekter und sich der Mittel der Komik bedienender Form, auf die Vermittlung moralischer Maximen zielt und deshalb der lehrhaften Dichtung zugerechnet werden kann, ${ }^{54}$ haben in jüngerer Zeit insbesondere angelsächsische Satiretheoretiker deren offenen Charakter betont. Es ist vor allem Dustin Griffin, dem das Verdienst zukommt, die

\footnotetext{
${ }^{47}$ Zum Konfessionalisierungsparadigma und die in diesem Zusammenhang ausgelöste Diskussion vgl. den knappen Überblick in Stefan Ehrenpreis und Ute Lotz-Heumann: Reformation und konfessionelles Zeitalter. Darmstadt 2002, S. 62-71. Vgl. auch Michael Prinz: Sozialdisziplinierung und Konfessionalisierung. Neuere Fragestellungen in der Sozialgeschichte der frühen Neuzeit. In: Westfälische Forschungen 42 (1992), S. 1-25.

${ }^{48}$ Manuel Braun: Disziplinierung durch disziplinlose Texte? Der moraltheologische Ehediskurs und ein Leitparadigma der Frühneuzeitforschung. In: Daphnis (31) 2002, S. 413-467.

${ }^{49}$ Braun (wie Anm. 48), S. 425.

${ }^{50}$ Braun (wie Anm. 48), S. 457.

${ }^{51}$ Auf diesen Aspekt hat bereits Horst Langer hingewiesen (Langer (wie Anm. 9), S. 361f.).

${ }^{52}$ Zur ,Satire' vgl. Jürgen Brummack: Zu Begriff und Theorie der Satire. In: DVjs 45 (1971) [Sonderheft Forschungsreferate], S. 275-377; Helmut Arntzen: Satire in der deutschen Literatur. Geschichte und Theorie. Band 1: Vom 12. bis zum 17. Jahrhundert. Darmstadt 1989; Barbara Könneker: Satire im 16. Jahrhundert. Epoche - Werke - Wirkung. München 1991; Dustin Griffin: Satire: A Critical Reintroduction. Lexington 1994; Jürgen Brummack: Satire. In: Reallexikon der deutschen Literaturwissenschaft. Bd. II: H-O. Hrsg. von Harald Fricke. Berlin 2000, S. 355-360; Harald Kämmerer und Uwe Lindemann: Satire: Text \& Tendenz. Anglistik Amerikanistik. Berlin 2004; Charles A. Knight: The Literature of Satire. Cambridge 2004.

${ }^{53}$ Vgl. Brummack 1971 (wie Anm. 52), S. 286-327.

${ }^{54}$ Die Normbindung der Satire thematisiert in differenzierter Weise Könneker (wie Anm. 52), S. $14 \mathrm{ff}$.
} 
Erschienen in: Anthropologie und Medialität des Komischen im 17. Jahrhundert (1580-1730), S. 429-463, https://doi.org/10.1163/9789401205993 019, Leiden, Brill, 2015

Auffassung, die satirische Schreibweise ziele primär auf die Propagierung spezifischer ethischer Normen, einer ebenso grundsätzlichen wie überzeugenden Kritik unterzogen zu haben. Konstitutiv für die Satire ist demnach weniger ein festes moralisches Fundament, von dem aus eine als defizitär wahrgenommene Wirklichkeit denunziert wird, als vielmehr eine besondere Form des Sprechens, die Griffin als ,,a rhetoric of inquiry, a rhetoric of provocation, a rhetoric of display, a rhetoric of play“ beschreibt. ${ }^{55}$ Satire gründet nicht so sehr in verbindlichen Werten, sondern stellt Werte zur Diskussion, sie gibt nicht so sehr Antworten, sondern provoziert Fragen. Zentral für Griffins Satirekonzept ist nicht nur der offene Charakter satirischer Kommunikation, sondern auch die spezifische Rezeptionssituation, innerhalb derer sie ihre Funktionen entfaltet. Wie Griffin betont, eignet der Satire seit ihren Anfängen eine ,öffentliche' und eine ,performative' Dimension. ${ }^{56}$ Satire gedeiht in der Gegenwart eines Publikums, das sich als Akteur literarischer Kommunikation versteht und Allusionen auf reale Begebenheiten oder literarische Zusammenhänge zu entziffern in der Lage ist. Eine derart definierte Satire zeichnet sich durch einen ludischen Zug aus, sie ist, in den Worten Griffins, , [an] intellectual play of irony and phantasy“ ${ }^{57} \mathrm{Zu}$ den Voraussetzungen für eine Blüte satirischer Literatur zählt Griffin folgerichtig weniger historische Umbrüche, auf die im Modus der Satire reagiert werden kann, als vielmehr das Vorhandensein einer zahlenmäßig begrenzten, sozial tendenziell homogenen, meist in einem städtischen Kontext angesiedelten Kommunikationsgemeinschaft, die einerseits mit den seit der Antike tradierten literarischen Konventionen der Satire vertraut ist und andererseits eine hinreichende Affinität zu Formen komischer Darstellung aufweist. ${ }^{58}$ Das Vergnügen, das die Satire ihren Adressaten bereitet, wurzelt nach Griffin denn auch weniger in der individuellen Affirmation als vielmehr in der kollektiven Reflexion zeitgenössischer Normen und der sich damit verbindenden lebensweltlichen Erfahrungen. ${ }^{59}$

Wenn Griffin auf dem offenen Charakter der Satire beharrt, kann er anknüpfen an ältere Traditionen, etwa diejenige der neulateinischen , satyra ludens', deren Rätselspiel es einem gebildeten Publikum ermöglichte, die eigene kulturelle Kompetenz zu erfahren und zu genießen. ${ }^{60}$ Die von Griffin postulierte Dialogisierung von Normen durch deren Verkehrung wiederum hat bereits Michail M. Bachtin in seinen auf der Analyse des Karnevals fußenden romantheoretischen Überlegungen hervorgehoben. ${ }^{61}$ Griffins Thesen sind demnach nicht neu, sie fokussieren jedoch in aller Entschiedenheit jenen Aspekt von Satire, der im Folgenden an einem Beispiel konkretisiert und vertieft werden soll.

Im Jahre 1640 ist in Nürnberg ein Flugblatt erschienen, das den Titel trägt Gemeiner Weiber Mandat/Darinnen vermeldet vnd angezeigt wird/von jhren Freyheiten/mit welchen sie drey Jahr lang in einem Sommer begabt seynd/ auff welche sich die M(nner verhalten sollen/ bey Peen vnd Straff/ wie hernach folget. ${ }^{62}$ Das Mandat, das in seinem Aufbau dem Schema der zeitgenössischen Urkundenpraxis folgt und den Kanzleistil des 17. Jahrhunderts parodiert, beginnt mit der intitulatio (,Feminarius/ Obrister Gubernator vnd Schutzherr der Weiber [...]/

\footnotetext{
${ }^{55}$ Griffin (wie Anm. 52), S. 39.

${ }^{56}$ Griffin (wie Anm. 52), S. $71 f$.

${ }^{57}$ Griffin (wie Anm. 52), S. 84.

${ }^{58}$ Vgl. Griffin (wie Anm. 52), S. $136 f$.

${ }^{59}$ Griffin (wie Anm. 52), S. 186.

${ }^{60}$ Vgl. Könneker (wie Anm. 52), S. 49.

${ }^{61}$ Vgl. Michail M. Bachtin: Die Ästhetik des Wortes. Hrsg. und eingeleitet von Rainer Grübel. Übersetzt von Rainer Grübel und Sabine Reese. Frankfurt/M. 1979, sowie Michail M. Bachtin: Literatur und Karneval. Zur Romantheorie und Lachkultur. Übersetzt von Alexander Kaempfe. Frankfurt/M., Berlin und Wien 1985. ${ }^{62}$ Harms/Kemp (wie Anm. 16), Nr. 27. Auf eine mögliche Vorlage dieses Flugblattes hat Michael Schilling aufmerksam gemacht (vgl. Schilling (wie Anm. 45), S. 235, Abb. 32). Eine Variante des Blattes ist abgedruckt in Alfred Kind: Die Weiberherrschaft in der Geschichte der Menschheit. Bd. 2. Wien 1930, S. 400a. Zu den Weiber- und Männer-Mandaten vgl. auch Kunzle (wie Anm. 13), S. 236-241.
} 
Erschienen in: Anthropologie und Medialität des Komischen im 17. Jahrhundert (1580-1730), S. 429-463, https://doi.org/10.1163/9789401205993 019, Leiden, Brill, 2015

Herr zu Plauderberg/ Schnadermarck vnd Waschhausen"); es folgen die inscriptio und salutatio („Entbieten allen vnd jeden vnsern lieben Getrewen/ Vnsere Gnad vnd willige Dienst bevor"), bevor die promulgatio und die narratio den Anlass für das Dekret, die Klage der Frauen über ihre tyrannischen Männer, bekannt geben. Die dispositio als ausführlichster Teil des Mandats nennt die den Männern für einen Zeitraum von drei Jahren auferlegten Pflichten: sie sollen ihren Frauen unbedingten Gehorsam erweisen, sie sollen im Winter früh aufstehen, die Stube reinigen und heizen und ihre Frauen mit einer warmen Weinsuppe wecken, sie sollen ihre Frauen für Festlichkeiten schmücken, in deren Abwesenheit das Haus säubern und sie Nachts mit einer Fackel nach Hause geleiten, sie sollen ihren Frauen ihr Vermögen überlassen und es tolerieren, dass ihre Frauen sich dem Spiel hingeben und sie sollen schließlich dulden, dass ihre Frauen sie mit der Rute züchtigen. Der zwischen Titel und Mandat eingefügte Kupferstich illustriert die durch das Dekret geforderten Verhaltensweisen idealer Ehemänner. Er zeigt in simultaner Darstellung einen die Stube kehrenden und ein Hemd über den Ofen hängenden Mann vor einem Alkoven, in dem eine Frau schläft, einen vor einer prächtig gekleideten Frau knienden und ihren Rock bürstenden Mann, einen Mann, der eine Dame mit einer Fackel geleitet, einen Mann, der einer an einem Tisch sitzenden Frau mit unterwürfiger Geste Geld überreicht, einen Mann, der eine mit einem anderen Mann zechende Dame bedient sowie einen knienden Mann, der von einer Frau auf das entblößte Hinterteil geschlagen wird. Auf den Mandatstext folgen eine gereimte M(nner Lamentation und eine Weiber Defension, die ein Siegel umrahmen, das den FEMINARIVS SIE MANORVM, eine auf einem Thron sitzende Frau, darstellt.

In direktem Bezug zum vorgängig beschriebenen Flugblatt steht M(nner Mandat. Frommer) Ehrliebender/ Tugentsamer Erbarer M(nner Mandat/ darin angezeigt vorgtbildet [!] vnd vermeldet wirdt/Von der M(nner Privilegien/Freyheiten/ vnnd Gnaden/mit welchen sie Gott der Allm(chtig im anfang der Erschaffung der Welt im heiligen Paradeiß miltig: reich vnd glФckselig begabet/ gesegnet/ vnd zu herrschern oder Oberherrn vber deß Feminarij Mundt/ Halß vnd gantzer Leib geordnet hat. Denen sich ein jeder frommer Feminarius soll vnd muß bequemen/ bey Straff jhrer außbannung/verlust aller Ehr/vnd Freundlichkeit/ so allen Feminarischen haderkatzen soll ohne einige vbersehung zugef Фget werden [...]. ${ }^{63}$ Der Aufbau des Textteils folgt demjenigen von Gemeiner Weiber Mandat: in der fiktiven intitulatio bezeichnet sich der Sprechende als „Masculus Vir, GroßFФrst vnd Oberherr vber Feminarius", die auf die inscriptio, die salutatio und die promulgatio folgende narratio verweist auf die Leiden, welche Gemeiner Weiber Mandat über die Ehemänner gebracht habe und äußert die Absicht, ,daß dieser stoltzen auffgeblasenen Hoffertigen Feminarien Mandat vnd Befelch mit bestendigen rationibus widerlegt/ bestritten/ vnd vnserer gesambten Masculorum Virorum Hochansehentlicher respect Ehr vnd auctoritet Reputirlich conservirt/ vnd von nun an biß zu allen Zeiten erhalten werde. "Wie auch in Gemeiner Weiber Mandat werden den Ehefrauen in der Folge fünf Pflichten auferlegt: unbedingter Gehorsam dem Gatten gegenüber, die Bereitschaft, ihm seinen wohlverdienten Schlaf zu gewähren und seine „Reuschlein“ tolerieren, der Wille, sich ihm, wenn sie ihn erzürnt haben, zu unterwerfen und durch allerlei Wohltaten zu besänftigen, die Fähigkeit, den Lebensunterhalt für die Familie zu gewährleisten und ihren Mann reichlich mit Geld zu versorgen sowie die aufrichtige Liebe zu ihrem Mann. Wie auch in Gemeiner Weiber Mandat dient in M(nner Mandat die Illustration einer Veranschaulichung des in diesem Fall von den Frauen geforderten Verhaltens. Sie stellt eine Frau dar, die ihren Mann zärtlich begrüßt, den Kamin einheizt, ihren Mann bei Tisch bedient, die Stube kehrt, seinen Schlaf bewacht, sich von ihm prügeln lässt und ihm Geld

\footnotetext{
${ }^{63}$ Harms/Kemp (wie Anm. 16), Nr. 28. Vgl. den Hinweis auf ein früher erschienenes ,Männermandat' in Schilling (wie Anm. 45), S. 235. Das betreffende Flugblatt ist abgedruckt in Hofmann-Randall (wie Anm. 11), S. 355, A X I.
} 
Erschienen in: Anthropologie und Medialität des Komischen im 17. Jahrhundert (1580-1730), S. 429-463, https://doi.org/10.1163/9789401205993 019, Leiden, Brill, 2015

überreicht. Im Zentrum der Abbildung thront der „Vir Masculus“ mit Gefolge, vor ihm eine kniende und eine in leicht gebeugter Haltung verharrende Frau als Repräsentatinnen der Ehefrauen.

Ein drittes, durch Paul Fürst verlegtes Flugblatt schließlich, Newer=ffneter Ernsthaffter/ hochstraffw Фrdiger vnd vnverbr Фchlicher M(nnerbefehlich/Abgegangen An alle nichtswichtige schlechtdichtige Gernem(nner, stellt im Rückgriff auf M(nner Mandat ${ }^{64}$ vier Forderungen an Ehefrauen, die die bereits in Gemeiner Weiber Mandat und M(nner Mandat offenkundige Ironie der Darstellung auf die Spitze treiben: Die Frau schulde ihrem Mann nicht nur Gehorsam, sie habe ihn zum Müßiggang und zum Alkoholgenuss zu ermutigen, solle ihn um Verzeihung bitten, wenn er sie im Rausch geschlagen habe und sei verpflichtet, ihn mit „Geld vnd Gold“ zu überhäufen und seine Schulden bereitwillig zu bezahlen. Die Darstellung vertauschter Geschlechterrollen in Gemeiner Weiber Mandat legt es nahe, das Flugblatt in der Tradition des mundus inversus zu verorten und die es charakterisierenden komischen Inversionsfiguren als Appell zu deuten, eine aus den Fugen geratene Welt in ihrer Ordnung wiederherzustellen. Gestützt wird diese Interpretation nicht nur durch den

Forderungskatalog in der dispositio und die damit korrespondierende graphische Gestaltung des Einblattdrucks, sondern auch durch die „M(nner Lamentation“, in der auf den Krebs als Emblem der, Verkehrten Welt' hingewiesen wird. M(nner Mandat wäre dann als Versuch zu lesen, jenes Normensystem wieder zur Geltung zu bringen, das durch Gemeiner Weiber Mandat aus den Angeln gehoben worden war. Eine genauere Lektüre der Scherzmandate macht nun allerdings deutlich, dass die Dinge komplizierter liegen. Zwar alludieren Text und Illustration der vorgängig beschriebenen Flugblätter an das motivische Repertoire der ,Verkehrten Welt' und die auf die weibliche Schwatzhaftigkeit gemünzten sprachlichen Formeln sowie den in Gemeiner Weiber Mandat zum Ausdruck gelangenden Wunsch der Frauen nach Unterordnung des Mannes darf man durchaus als den literarischen Topos des ,bösen Weibs' bemühende Kritik an unbotmäßigen Ehegattinnen verstehen; die Hyperbolik der Darstellung enthüllt jedoch sehr schnell den ironischen Charakter von Gemeiner Weiber Mandat. Dass die Ironie sich nicht nur gegen die Frauen, sondern auch gegen die Männer richtet, belegen die die Geschlechterordnung scheinbar restitutierenden ,Männermandate'. Wenn es in Newer=ffneter M(nnerbefehlich nun die Frau ist, die ihren dem Müßiggang frönenden Mann bedient, seine alkoholischen Exzesse erträgt, sich der ungebändigten eheherrlichen Gewaltausübung ohne Widerstand aussetzt und ihn reichlich mit Geld versorgt, heißt dies nicht, dass damit jener Zustand hergestellt wäre, der dem zeitgenössischen Ideal ehelichen Zusammenlebens entspricht, das in Gemeiner Weiber Mandat auf den Kopf gestellt erscheint. Der Fokus des Angriffs verschiebt sich vielmehr auf die Männer als denjenigen, die ihren Frauen den sozialen Umgang mit ihren Geschlechtsgenossinnen verbieten und zugleich einen Großteil ihrer Zeit im Wirtshaus verbringen, die ihre Gattin im Alkoholrausch ohne ersichtlichen Grund misshandeln oder das von der Ehefrau erarbeitete Geld verschleudern und damit den ökonomischen Wohlstand der Familie bedrohen. Dass ein solches Verhalten in krassem Gegensatz zur religiös fundierten, rechtlich sanktionierten und durch die Institutionen der frühneuzeitlichen ,Policey' kontrollierten Auffassung der Rolle des Ehemannes steht, liegt auf der Hand. ${ }^{65}$ Wenn demnach der Ehemann die in Newer ffneter M(nnerbefehlich

\footnotetext{
${ }^{64}$ Die Nähe zu M(nner Mandat ergibt sich nicht zuletzt aus dem Umstand, dass es sich bei der Graphik von Newer ffneter M(nnerbefehlich um einen seitenverkehrten Nachstich der Illustration von M(nner Mandat handelt.

${ }^{65}$ Beispielhaft lässt sich dies mit Blick auf den Status des Trinkens verdeutlichen: Wie B. Ann Tlusty herausgestellt hat, gehörte der öffentliche Alkoholkonsum, der für Frauen mit Ehrverlust verbunden sein konnte (vgl. B. Ann Tlusty: Crossing Gender Boundaries: Women as Drunkards in Early Modern Augsburg. In: Ehrkonzepte in der Frühen Neuzeit. Identitäten und Abgrenzungen. Hrsg. von Sybille Backmann, Hans-Jörg Künast, Sabine Ullmann und B. Ann Tlusty. Berlin 1998 (= Colloquia Augustana 8), S. 185-198), anders, als
} 
Erschienen in: Anthropologie und Medialität des Komischen im 17. Jahrhundert (1580-1730), S. 429-463, https://doi.org/10.1163/9789401205993 019, Leiden, Brill, 2015

empfohlenen Verhaltensmodi praktiziert, handelt er genauso verkehrt, wie seine Frau, die ebendiese Verhaltensmodi unterstützt, statt ihren Mann zu normgerechtem Handeln zu bewegen.

Bemerkenswert ist nun, mit welchen Mitteln in den genannten Flugblättern die satirische Denunziation bewerkstelligt wird. Zunächst fällt auf, dass sich die Darstellung in einem dichten Netz intertextueller Bezüge bewegt, welches das gesamte Korpus satirischer Literatur zur Ehe umfasst. So bilden nicht nur die dem Topos der in M(nner Mandat wörtlich zitierten Mala Mulier verpflichteten Beschreibungsmuster weiblichen Verhaltens, sondern auch der rekurrierende Hinweis auf die Wirtshausbesuche des Ehegatten Konstanten innerhalb der Flugblattüberlieferung zum Thema ,Weiberregiment'. Die Formulierung ,,vnd sollen die jenigen Frawen/ oder Weiber/ (die solches Mandat nit begehren/ sondern jhren M(nnern gerne das Mannliche Regiment verg=nnen vnd lassen/) hiermit keinswegs verstanden oder gemeinet seyn, “ (Gemeiner Weiber Mandat) wiederum zitiert jene Ausschlussformel für fromme Hausfrauen, die auf so gut wie allen publizistischen Inszenierungen eigensinniger Ehegattinnen begegnet, ${ }^{66}$ und die Bezeichnung ,SIE MANORVM“ im Siegel des Feminarius (Gemeiner Weiber Mandat) verweist auf den auch in anderen Einblattdrucken verwendeten Begriff des ,Sieman' für herrschsüchtige Frauen. ${ }^{67}$ Es sind derartige Andeutungen, welche die Ehesatire als diskursive Formation in den Blick rücken und zu einer Auseinandersetzung mit den sie konstituierenden Auffassungen des ehelichen Verhältnisses zwischen Mann und Frau provozieren, die für das zeitgenössische Publikum einen erheblichen Reiz dargestellt haben dürften. Nicht weniger provokativ und zugleich unterhaltend sind die rhetorischen Strategien, die jene Reibung zwischen Darstellungsmodus und dargestellter Wirklichkeit evozieren, die zu den wichtigsten Katalysatoren komischen Vergnügens zählt. Wenn männliche Trunksucht, die Einnahme eines „K(nnleins Wein“ verharmlosend als „Reuschlein“, die sich gegen ihren alkoholisierten Gatten zur Wehr setzende Frau hingegen als „schnauffende Haderkatz“ bezeichnet wird (M(nner Mandat), wenn der Frau auferlegt wird, ,gleich einer Schneck“ das Haus zu hüten, während die Wirtshausaufenthalte des Mannes mit den Worten „die B(ncke haben Leim Jm Wirthshauß offt vnd viel“" entschuldigt werden (Newerffneter $M$ (nnerbefehlich), soll dies zum Widerspruch reizen - und zum Gelächter. Der komische Effekt resultiert nicht nur aus der Hyperbolik der Darstellung, aus Wortwitz (beispielsweise „PrФgelsuppen“ oder „,vngebrandte Asche“ für Holzknüppel in Newer=ffneter

M(nnerbefehlich), aus sprachlicher Inkommensurabilität oder aus der hier beispielhaft zitierten, zum Lachen reizenden Metaphorik, er verdankt sich auch jenen relativierenden Einschüben, welche die Diskrepanz zwischen normativer Theorie und lebensweltlicher Praxis entlarven: Sowohl in Gemeiner Weiber Mandat als auch in M(nner Mandat werden die dem Mann bzw. der Frau gegenüber erhobenen Forderungen systematisch unterminiert durch

\footnotetext{
dies zum Teil in der älteren historischen Forschung behauptet wurde, in der Frühen Neuzeit zu den Privilegien ehrenhafter Männer und der Besuch von Wirthäusern galt als Ausweis sozialer Integration (vgl. B. Ann Tlusty: Bacchus and Civic Order. The Culture of Drink in Early Modern Germany. Charlottesville und London 2001). Auch Tlusty betont jedoch, dass Kontrollverlust infolge von Alkoholkonsum als unehrenhaft galt und sanktioniert werden konnte. Dass übermäßiger Alkoholkonsum von Männern eine ernsthafte Bedrohung nicht nur des ehelichen Friedens, sondern auch der männlichen Autorität innerhalb der Ehe darstellte und deswegen von den Obrigkeiten mit Skepsis betrachtet und bisweilen bestraft wurde, hat Lyndal Roper am Beispiel der Augsburger Ehegerichtsbarkeit gezeigt (vgl. Roper (wie Anm. 43), S. 156-160). Zur Darstellung von Trinken auf Einblattdrucken vgl. B. Ann Tlusty: Trinken und Trinker auf illustrierten Flugblättern. In: Das illustrierte Flugblatt in der Kultur der Frühen Neuzeit. Wolfenbütteler Arbeitsgespräch 1997. Hrsg. von Wolfgang Harms und Michael Schilling. Frankfurt/M. 1998 (= Mikrokosmos 50), S. 177-203.

${ }^{66}$ So heißt es etwa in Offt Probiertes und Bewährtes Recept oder Artzneÿ für die bösse Kranckheit der unartigen Weiber „Doch diese meint man nicht,/ die man verst(ndig weiß, Wer eine s=lche hat/ der wohnt im Paradeiß“ (Harms/Schilling (wie Anm. 4), Nr. 115).

${ }^{67}$ Zu Begriff und Phänomen des ,Sieman’ vgl. Moser (wie Anm. 7), S. 227-232.
} 
Erschienen in: Anthropologie und Medialität des Komischen im 17. Jahrhundert (1580-1730), S. 429-463, https://doi.org/10.1163/9789401205993 019, Leiden, Brill, 2015

Klammerbemerkungen wie „wann er will“, „,wanns dem Mann gef(1lt“, „,nach seinem Belieben“ oder ,,jeder Mann ders gerne thut" bzw. „Herr zu vnd im Hauß/ (wann Feminarius ist darauß)“. Damit wird die Realisierbarkeit der Dekrete bereits im Moment ihrer öffentlichen Verkündigung hinterfragt und die Entscheidungsbefugnis des Mannes bzw. der Frau ironisch restitutiert.

Dafür, dass das in Gemeiner Weiber Mandat, M(nner Mandat und Newerfffneter M(nnerbefehlich beschworene Ideal ehelicher Interaktion eine Chimäre darstellt, sprechen nicht nur die Vielzahl relativierender Klammerbemerkungen, sondern auch die wiederholten Anspielungen auf das ,Schlaraffenland', als jenem utopischem Ort, der sinnlichen Genuss im Überfluss verspricht. Wenn der Ehemann in Gemeiner Weiber Mandat dazu verpflichtet wird, seiner Gattin ,gebratenen Fisch [...] Capaunen/ oder Lerchen“" zu reichen; wenn die Ehefrau in M(nner Mandat ihren Gatten mit „Leckerbißlein“ zu besänftigen, zum Müßiggang zu ermuntern und reichlich mit Geld zu versorgen hat und ihn in Newer=ffneter M(nnerbefehlich mit „Krebs/ HФner/ Tauben“ und Fischen bewirten soll, klingt jene Wunschphantasie ungehemmter Bedürfnisbefriedigung an, über deren illusionären Charakter bei den Zeitgenossen keine Zweifel bestanden.

Zum Lachen gereizt haben dürften schließlich und vor allem die mehr oder weniger offenkundigen Anzüglichkeiten, die die Flugblätter enthalten. Die Formulierung ,wo sie [die Ehefrau, A.d.V.] etwan ein Lust ank(me (vnd er nicht $\mathrm{m}=\mathrm{chte}$ )“ in Gemeiner Weiber Mandat enthält ebenso eine erotische Konnotation wie der Hinweis auf die „Nachtarbeit“ des Mannes in M(nner Mandat. Vor allem jedoch ist es Newer=ffneter M(nnerbefehlich, der auf das komische Potential obszöner Allusionen vertraut. Die Bezeichnung „Kammerk(tzlein“ für die Ehefrau sowie der an die Männer gerichtete Ratschlag „Jm Fall sie diß nicht thut/ will jhm nicht bald auffhupffen Vnd zeucht deß Mundes Schwerdt/ kan er die Scheide klupffen“ zielen eindeutig-zweideutig auf die erotische Beziehung zwischen Frau und Mann. In diesem Kontext gewinnt der Begriff „Klappertasche“ („Ein Fraw die diß nicht thut vom Manne sey gepufft/ Trag PrФgelsuppen auff/ vnd vngebrandte Asche Die stillt den Weiberzorn vnd jhre Klappertasche“) eine zusätzliche Bedeutung: Er bezeichnet nicht nur das lose Mundwerk der Frau, das durch körperliche Züchtigung unter Kontrolle gebracht werden soll, sondern auch das Geschlechtsteil der Frau als körperlichem Kristallisationspunkt weiblichen Begehrens. ${ }^{68}$ Die Feststellung „Alle M(nner mФssen siegen/ Alle Weiber vnten liegen“ und die Bemerkung, es hätte sich noch keine Frau darüber beschwert, dass ihr Mann sie nächtens geschwängert habe (,Man hat noch nie geh=ret Daß sich ein Weib beschweret/ Daß jhr der Mann zu Nachte Auß Ehstand Wehstand machte") tragen ebenfalls zu einer Entschärfung des ehelichen Geschlechterkampfes bei, indem sie die Unterordnung der Frau und die im Ehediskurs rekurrierende Vorstellung der Ehe als ,Wehestand' ins Sexuelle wenden und damit dem Gelächter preisgeben.

Der zugegebenermaßen summarische Blick auf ein durch engste intermediale Bezüge als zusammengehörig erkennbares Ensemble von Flugblättern dürfte deutlich gemacht haben, dass eine Lektüre, die den Ehediskurs im 16. und 17. Jahrhunderts als Teil des zeitgenössischen Ordnungsdiskurses deutet und die in diesem Zusammenhang publizierten Einblattdrucke ausschließlich unter moraldidaktischen und disziplinierenden Gesichtspunkten betrachtet, notwendigerweise zu Verkürzungen führt. Zwar ist M(nner Mandat keinesfalls frei von Äußerungen, die als Ausdruck eines normativen Eheverständnisses gelten können, und

\footnotetext{
${ }^{68}$ Die literarisch vielfach bezeugte Bedeutung von ,weibliche Scham' für ,Tasche' bildet beispielsweise im bereits erwähnten Flugblatt Kurtzweilige Erzehlung einer Frawen im Elsaß/ welche bey n (chtlicher Weil jhrem Mann die Taschen geraumt/vnd wie sie sich selber drФber verrahten $m \Phi$ ssen/ etc. den Ausgangspunkt für die zotenhafte Erzählung eines Ereignisses, das sich angeblich im Elsass abgespielt haben soll (vgl. Harms/Schilling (wie Anm. 4), Nr. 110).
} 
Erschienen in: Anthropologie und Medialität des Komischen im 17. Jahrhundert (1580-1730), S. 429-463, https://doi.org/10.1163/9789401205993 019, Leiden, Brill, 2015

erweist sich deshalb als weitaus ambivalenter, als es auf den ersten Blick scheinen möchte, ${ }^{69}$ dennoch ist Vorsicht geboten, wenn es darum geht, die Funktion von Flugblättern wie Gemeiner Weiber Mandat, M(nner Mandat oder Newer ffneter M(nnerbefehlich zu bestimmen. Das Verhältnis zwischen Eheleuten und die ihnen angemessenen Interaktionsmuster werden weniger dekretiert als vielmehr ironisch relativiert, die Männern und Frauen zugeordneten Geschlechterrollen weniger mit autoritativem Gestus postuliert als vielmehr auf spielerische Weise miteinander konfrontiert. Dabei erscheint das Verhältnis zwischen den Ehegatten keinesfalls so asymmetrisch, wie es das dem frühneuzeitlichen Ehediskurs zugrunde liegende Axiom von der Suprematie des Mannes vermuten lassen könnte. Nicht nur die Tatsache, dass in den untersuchten Scherzdekreten das Privileg der Herrschaft über das jeweils andere Geschlecht sowohl den Ehemännern als auch den Ehefrauen zugestanden und zugleich verweigert wird, auch die Gegenüberstellung von männlicher Stärke und weiblicher List in Newerffneter M(nnerbefehlich verweist auf Handlungsspielräume von Frauen: Die Veranschaulichung der „Mænersterck“ im Bild eines mit Keule und Stock bewaffneten Löwen, die von der „Weiberlist“, versinnbildlicht durch den einen Stein in seinen Krallen haltenden Kranich als Emblem der Wachsamkeit ${ }^{70}$ und die Schlange als Attribut der Prudentia, ${ }^{71}$ überwunden wird (,M(nner Siegel dieses ist Das erbricht der Weiber List"), konterkariert die Vorstellung einer bedingungslosen Unterwerfung der Frau unter den Mann. Sowohl die männlichen als auch die weiblichen Ehegatten verfügen, dies die Botschaft, über jeweils geschlechtsspezifische Möglichkeiten, ihre Vorstellungen und Bedürfnisse zu artikulieren und in die Wirklichkeit umzusetzen; die Qualität der ehelichen Beziehung zwischen Mann und Frau erscheint unter dieser Prämisse nicht als Resultat präskriptiver Setzungen, sondern als Ergebnis von Aushandlungsprozessen. Worauf Gemeiner Weiber Mandat, M(nner Mandat und Newer=ffneter M(nnerbefehlich zielen, ist, so das Fazit, nicht so sehr die Reetablierung in die Krise geratener Ordnungsvorstellungen; was die genannten Einblattdrucke leisten, ist vielmehr eine Problematisierung und Diskursivierung die Ehe betreffender Normen.

Plausibilität gewinnt die hier formulierte These, wenn man das Augenmerk auf die Rezeptionsmodi frühneuzeitlicher Bildpublizistik richtet. Die Rekonstruktion der Kommunikationszusammenhänge, innerhalb derer die im 16. und 17. Jahrhundert veröffentlichten Flugblätter ihre Wirkung entfalteten, gehört zu jenen Fragestellungen, auf die die medienhistorische Forschung bislang noch kaum befriedigende Antworten gefunden hat. Immerhin besteht Konsens darüber, dass als Adressaten frühneuzeitlicher Einblattdrucke Angehörige so gut wie aller gesellschaftlicher Schichten in Frage kamen und dass sich mit Blick auf die vormoderne Bildpublizistik vielfältige Gebrauchsmöglichkeiten beschreiben lassen. ${ }^{72}$ Sie diente politisch Interessierten als Instrument der Meinungsbildung, bildete das Sammelobjekt bibliomaner Adliger und den Gegenstand von Tauschbeziehungen, war Bestandteil frühneuzeitlicher Frömmigkeitspraxis oder fungierte als Wandschmuck in öffentlichen und privaten Gebäuden. So offenkundig wie die Polyfunktionalität von frühneuzeitlicher Bildpublizistik ist deren Affinität zu kollektiven, Schriftlichkeit und

\footnotetext{
${ }^{69}$ Dies gilt etwa dann, wenn der Frau Unterordnung befohlen wird „,wofern er [der Ehemann, A.d.V.] nicht ausser den schrancken trette“ (M(nner Mandat).

${ }^{70}$ Vgl. Emblemata. Handbuch zur Sinnbildkunst des XVI. und XVII. Jahrhunderts. Hrsg. von Arthur Henkel und Albrecht Schöne. Stuttgart 1967, Sp. 820f.

${ }^{71}$ Im Rekurs auf das biblische Wort von der Klugheit der Schlangen (Mt 10, 16) wird die Schlange beispielsweise in Cesare Ripas Iconologia zu den Attributen der „Prudenza“ gezählt (vgl. Cesare Ripa: Iconologia [...] In Padoua per Pietro Paolo Tozzi M.DX.XI [Reprint New York und London 1976], S. 441ff. ${ }^{72}$ Mit der Frage, wer als Abnehmer von Flugblättern in Frage kam, hat sich Michael Schilling ausführlicher auseinandergesetzt (Schilling: Bildpublizistik (wie Anm. 45), S. 40-53). In seiner grundlegenden Studie zur Bildpublizistik der Frühen Neuzeit finden sich auch vereinzelte Hinweise auf Verwendungszusammenhänge von Einblattdrucken.
} 
Erschienen in: Anthropologie und Medialität des Komischen im 17. Jahrhundert (1580-1730), S. 429-463, https://doi.org/10.1163/9789401205993 019, Leiden, Brill, 2015

Mündlichkeit amalgamierenden Formen der Kommunikation. Es spricht deshalb viel dafür, dass Einblattdrucke wie Gemeiner Weiber Mandat, M(nner Mandat und Newerfffneter $M$ (nnerbefehlich weniger im Kontext karnevalesken Brauchtums eine Rolle spielten, wie dies Natalie Zemon Davies behauptet hat, ${ }^{73}$ sondern im Rahmen geselliger Erzählsituationen Verwendung fanden, wie sie auch und gerade für jene schwankhafte Literatur konstitutiv sind, zu der sie in enger Beziehung stehen. Elfriede Moser-Rath hat in ihrer monographischen Studie zu Schwankdichtung der Frühen Neuzeit herausgestellt, in welchem Maße eine ursprünglich in adeligen und gelehrten Milieus gepflegte literarische Konversationskultur sich im 17. Jahrhundert in städtischen Bürgerschichten durchzusetzen vermochte. ${ }^{74}$ Anlässe zu Geselligkeit gab es, will man den Kompilatoren barocker Erzählsammlungen Glauben schenken, reichlich. Genannt werden etwa ,Gastereyen', ,Wanderschaften' im Sinne von Reisen, studentische Zusammenkünfte, Kuraufenthalte; darüber hinaus werden immer wieder die langen Sommertage und Winternächte bemüht, die Gelegenheit zu geselligem Austausch böten. ${ }^{75}$ Auch wenn sich die Annahme kaum durch empirische Rezeptionsstudien untermauern lassen wird, scheint es nicht abwegig, die satirischen Einblattdrucke zum Thema Ehe zu jenen Medien bzw. Genres zu zählen, die an der Herausbildung und der Erfolgsgeschichte literarisch basierter bürgerlicher Kommunikationskultur erheblichen Anteil hatten. Sie zielen nämlich weniger auf eine individuelle als vielmehr auf eine kollektive Rezeption, verstehen sich als Katalysator von ,Gesprächspielen' in denen all jene Themen in kontroverser Weise verhandelt werden konnten, die den weiten Horizont frühneuzeitlicher Erfahrung ausmachten.

Unter der Prämisse, dass die vorgängig erörterten Einblattdrucke auf eine kollektive Rezeption angelegt sind, lässt sich deren Funktion abschließend noch präziser bestimmen, als dies bisher getan wurde: Als satirische Artefakte ermöglichen sie mittels der von Griffin für die Satire als konstitutiv postulierten ,rhetoric of inquiry', ,rhetoric of provocation', ,rhetoric of display' und ,rhetoric of play' jene kontroverse Auseinandersetzung mit lebensweltlichen Normen, Erfahrungen und Praktiken, welche auch für die gesellige Rezeption der Schwankdichtung und die Tradition des ,Gesprächspiels' charakteristisch ist. Wenn, wie dies mit Blick auf die Frauenzimmer Gesprächspiele (1641-1649) des Nürnberger Patriziers Georg Philipp Harsdörffer herausgestellt wurde, die darin inszenierte dialogische Kommunikation auf dem Verfahren einer ,deliberativen Spiel-Rhetorik“ beruht, in der es weniger um klare Urteile als vielmehr um die perspektivenreiche Behandlung strittiger Fragen geht ${ }^{76}$ wenn also ,Gesprächspiele' als kulturelle Praxis zu verstehen sind, die es einer sowohl Männer als auch Frauen umfassenden Kommunikationsgemeinschaft ermöglicht, sich

\footnotetext{
${ }^{73}$ Natalie Zemon Davies stellt die im 17. Jahrhundert in Nürnberg gedruckten Weibermandate in den Zusammenhang des durch den Karneval generierten , ordo inversus', ohne dies allerdings durch Quellen zu belegen (vgl. Natalie Zemon Davies: Humanismus, Narrenherrschaft und die Riten der Gewalt. Gesellschaft und Kultur im frühneuzeitlichen Frankreich. Aus dem Amerikanischen von Nele Löw Beer. Frankfurt/M. 1987, S. 161).

${ }^{74}$ Die durch hohe Auflagen bezeugte Publikumswirksamkeit von schwankhaften Erzählsammlungen, die für den Vortrag in geselliger Runde gedacht waren - zu nennen wären hier etwa Johann L. Talitz von Lichtensees Kurtzweyliger Reyßgespahn (1645) oder Peter de Memels Lustige Gesellschaft (1656) - wertet Elfriede MoserRath als ein wichtiges Indiz für die Bedeutung, die dem geselligem Austausch über Literatur auch und seit dem 17. Jahrhundert verstärkt in bürgerlichen Kreisen zukam (vgl. Elfriede Moser-Rath: „Lustige Gesellschaft“. Schwank und Witz des 17. und 18. Jahrhunderts im kultur- und sozialgeschichtlichem Kontext. Stuttgart 1984, S. 19-36).

${ }^{75}$ Moser-Rath (wie Anm. 74), S. 50.

${ }^{76}$ Herbert Jaumann: Die Kommunikation findet in den Büchern statt. Zu Harsdörffers Literaturprogramm in den Gesprächspielen. In: Georg Philipp Harsdörffer. Ein deutscher Dichter und europäischer Gelehrter. Hrsg. von Italo Michele Battafarano. Bern 1991 (= IRIS 1), S. 163-179, hier S. 179.
} 
Erschienen in: Anthropologie und Medialität des Komischen im 17. Jahrhundert (1580-1730), S. 429-463, https://doi.org/10.1163/9789401205993 019, Leiden, Brill, 2015

gleichberechtigt über literarische und außerliterarische Fragen zu verständigen, ${ }^{77}$ wird einmal mehr deutlich, dass der Versuch, die Funktion satirischer Bildpublizistik zu ergründen, nicht allein von den sich in frühneuzeitlichen Einblattdrucken spiegelnden Diskurstraditionen ausgehen darf, sondern die Aufmerksamkeit auch auf jene performativen Praktiken zu richten hat, aus denen sich mögliche Wahrnehmungsmodi überhaupt erst erschließen lassen. In diesem Zusammenhang ist es wohl kaum zufällig, dass die Mehrzahl der aus dem 17. Jahrhundert überlieferten satirischen Einblattdrucke zum Thema ,Ehe' in Nürnberg gedruckt wurden. ${ }^{78}$ So sehr sie sich in mancher Hinsicht von Harsdörffers Frauenzimmer Gesprächspielen oder Sigmund von Birkens ebenfalls in Nürnberg gedruckter Pegnesischen Gesprächspielgesellschaft (1665) ${ }^{79}$ unterscheiden, dürfte ihr Erfolg nicht unwesentlich einer durch ein städtisches Bürgertum getragenen Konversationskultur zu verdanken sein, die auf immer neue literarische Impulse angewiesen war. ${ }^{80}$

Dass die hier interessierenden Flugblätter darauf angelegt sind, im Modus kollektiver Rezeption angeeignet zu werden, führt zu einem weiteren Befund. Als satirische Artefakte reizen sie zum Lachen und stiften damit das, was Werner Röcke und Hans Rudolf Velten jüngst als ,Lachgemeinschaft' bezeichnet haben. ${ }^{81}$ Die ,affiliative Funktion“"82 des Lachens ist in der Theorie des Komischen bereits früh erkannt worden. So hat etwa Anton C. Zijderveld aus soziologischer Warte daran erinnert, dass bereits Henri Bergson in seinem berühmten Essay über das Lachen, die kohäsionsstiftende Kraft gemeinschaftlichen Gelächters hervorgehoben hatte. ${ }^{83}$ Dem Lachen kommt dabei, so Zijderveld, eine doppelte Funktion zu: zum einen generiert es einen Raum, in dem Werte, Normen und Deutungsmuster einer Gesellschaft auf spielerische Weise einer Relativierung unterzogen werden können, ${ }^{84}$ zum andern, und darauf kommt es hier in besonderem Maße an, stiftet es ein Gefühl der Zusammengehörigkeit, stärkt es die kollektive Identität einer Gruppe. ${ }^{85}$ Dies geschieht keinesfalls nur dann, wenn eine ,Lachgemeinschaft' ihren Spott auf dasselbe Objekt richtet und sich derart ihres gemeinsamen Wertesystems bewusst wird, sondern auch dann, wenn es gelingt, divergierende Positionen innerhalb einer Gruppe auf vergnügliche Weise zu

\footnotetext{
${ }^{77}$ Italo Michele Battafarano hat darauf hingewiesen, dass der Titel von Harsdörffers Werk keineswegs auf einen rein weiblichen Adressatenkreis, sondern auf eine gleichberechtigte Gesprächsgemeinschaft von Frauen und Männern zielt (Italo Michele Battafarano: Harsdörffers italianisierender Versuch, durch die Integration der Frau das literarische Leben zu verfeinern. In: Georg Philipp Harsdörffer (wie Anm. 76), S. 267-286).

${ }^{78}$ David Kunzle hat festgestellt, dass die Ehe thematisierende Flugblätter eine eigentliche Spezialität Nürnbergs darstellten (vgl. Kunzle (wie Anm. 13), S. 227).

${ }^{79} \mathrm{Zu}$ Sigmund von Birkens Pegnesischer Gesprächspielgesellschaft vgl. Rosmarie Zeller: Spiel und

Konversation im Barock. Untersuchungen zu Harsdörffers ,Gesprächspielen', Berlin/New York 1974 (= Quellen und Forschungen zur Sprach- und Kulturgeschichte der germanischen Völker N.F. 58), S. 96f.

${ }^{80}$ Solange für Nürnberg keine Studien vorliegen, wie sie Erich Kleinschmidt für den südwestlichen deutschen Sprachraum betrieben hat (Stadt und Literatur in der Frühen Neuzeit. Voraussetzungen und Entfaltung im südwestdeutschen, elsässischen und schweizerischen Städteraum, Köln/Wien 1982 (= Literatur und Leben N.F. 22)), bleibt die besondere Affinität Nürnbergs zu aus der Romania importierten Modellen literarischer Kommunikation eine Hypothese. Dennoch hat bereits Rosmarie Zeller vermutet, dass die Häufigkeit, mit der ,Gesprächspiele' in zeitgenössischen Romanen begegnen, als Indiz dafür verstanden werden kann, dass derartige Praktiken nicht ausschließlich im Modus der Fiktion existierten (Zeller (wie Anm. 79), S. 56).

${ }^{81}$ Lachgemeinschaften. Kulturelle Inszenierungen und soziale Wirkungen von Gelächter im Mittelalter und in der Frühen Neuzeit. Hrsg. von Werner Röcke und Hans Rudolf Velten. Berlin/New York 2005 (= Trends in Medieval Philology 4).

${ }^{82}$ Röcke/Velten (wie Anm. 81), S. XI.

${ }^{83}$ Anton C. Zijderveld: A Sociological Theory of Humor and Laughter. In: Semiotik, Rhetorik und Soziologie des Lachens. Vergleichende Studien zum Funktionswandel des Lachens vom Mittelalter zur Gegenwart. Hrsg. von Lothar Fietz, Joerg O. Fichte und Hans-Werner Ludwig. Tübingen 1996, S. 37-45, hier S. 38.

${ }^{84}$ Vgl. Zijderveld (wie Anm. 83), S. 38: „Sociologically speaking humor can be defined as the social game people play with the values, norms and meanings of their society in general, or of the group or sub-group they live in."

${ }^{85}$ Vgl. Zijderveld (wie Anm. 83), S. 43f.
} 
Erschienen in: Anthropologie und Medialität des Komischen im 17. Jahrhundert (1580-1730), S. 429-463, https://doi.org/10.1163/9789401205993 019, Leiden, Brill, 2015

entschärfen, „Konflikte performativ aus[zu]spielen und somit [zu] lösen“ “ ${ }^{86}$ Den Rezipientenkreis satirischer Einblattdrucke zum Thema Ehe auf eine sich ihrer misogynen Auffassungen versichernde ,Lachgemeinschaft' „,bürgerliche[r], nationalistische[r], protestantische[r] Männer“ zu begrenzen, wie dies Malcolm Jones kürzlich mit Blick auf England getan hat, ist so gesehen verfehlt. ${ }^{87}$ Kennzeichnend für sich gleichermaßen an Männer und Frauen richtende publizistische Drucke wie Gemeiner Weiber Mandat, M(nner Mandat oder Newer=ffneter M(nnerbefehlich ist gerade, dass sie nicht einfach misogyne und misogame Topoi reproduzieren, sondern dass sie das Verhältnis zwischen den Ehegatten als Effekt reziprok aufeinander bezogener Geschlechternormen darstellen und damit auch eine Beurteilung männlicher Verhaltensweisen erlauben. Indem diese Beurteilung im konventionalisierten Rahmen eines Spiels erfolgt, wird ihr die Spitze gebrochen. Die diskursiv bewerkstelligte Hinterfragung geschlechtsspezifischer Stereotypen gewinnt nie den Charakter eines die realen Verhältnisse bedrohenden Umsturzversuches, sondern bleibt ein durch Lachen abgefedertes Spiel, in dem alternative Geschlechtermodelle auf nicht sanktionierbare Weise entworfen und verteidigt werden können.

Meine Überlegungen haben, so hoffe ich, deutlich gemacht, dass den im Medium des Flugblatts überlieferten Ehesatiren mit monokausalen Begründungsmustern kaum beizukommen ist. Es genügt nicht, deren literarische und ikonographische Konfiguration zu analysieren, es bedarf außerdem einer Berücksichtigung der historischen Kontexte, auf die sie rekurrieren, und es bedarf schließlich und insbesondere einer sorgfältigen Rekonstruktion der Kommunikationssituation, die deren in der Regel milieugebundene Rezeption bestimmte. Die Funktion oder besser die Funktionen von Einblattdrucken wie Gemeiner Weiber Mandat, M(nner Mandat und Newer=ffneter M(nnerbefehlich erweisen sich dann als weitaus komplexer, als sich aus einer oberflächlichen Betrachtung ergibt. Im Modus satirischer Provokation appellieren sie an die Adressaten, die im jeweiligen Scherzdekret zum Ausdruck gelangende Auffassung adäquaten männlichen bzw. weiblichen Verhaltens im Rahmen einer kontroversen Diskussion zu erörtern und ermutigen dazu, normative Setzungen im Dialog tentativ aufzulösen. Zugleich eröffnen sie einen intellektuellen und affektiven Spielraum, der unterschiedliche Reaktionsweisen ermöglicht: Die grotesk überzeichnete Darstellung inadäquater Verhaltensmuster kann den Adressaten als Bestätigung ihres eigenen, sozial adäquaten, Handelns dienen und damit normstabilisierend wirken; die satirische Verfremdung kann jedoch - im Sinne einer komischen ,Dialektik von Affirmation und Emanzipation' - ${ }^{88}$ auch eine kritische Auseinandersetzung mit hegemonialen Diskursformationen begünstigen und zu deren Relativierung führen. Die satirische Denunziation weiblicher Autorität muss nicht unbedingt abschreckend wirken, sie kann, vor allem bei den weiblichen Adressaten, auch Genugtuung über selbstbewusst handelnde Geschlechtsgenossinnen hervorrufen und die eigene weibliche Identität stärken; die Sublimierung des Geschlechterkampfes durch die Übertragung auf die Ebene eines literarisch legitimierten Schlagabtauschs kann jedoch auch zu einem Ausbalancieren geschlechtsbedingter Oppositionen beitragen und potentielle Konfliktfelder zwischen Mann und Frau durch gemeinsames Gelächter entschärfen. Die Schilderung ehelicher Exzesse kann, wie dies Michael Schilling betont hat, eine sozialpsychologisch entlastende Funktion entfalten, indem sie es den Rezipienten ermöglicht, an gesellschaftlich unterdrückten Wunschvorstellungen auf kontrollierte Weise teilzuhaben; ${ }^{89}$ die in den Scherzmandaten angelegte Diskursivierung der Geschlechterordnung kann außerdem und schließlich als Aufforderung verstanden werden, neuartige Interaktionsmuster

\footnotetext{
${ }^{86}$ Röcke/Velten (wie Anm. 81), S. XIV.

${ }^{87}$ Malcolm Jones: No laughing matter? Die Wiederentdeckung der komischen Flugblätter aus dem England des 17. Jahrhunderts. In: Röcke/Velten (wie Anm. 81), S. 289-329, hier S. 291.

${ }^{88}$ Vgl. Susanne Schäfer: Komik in Kultur und Kontext. München 1996. S. $28 f f$.

${ }^{89}$ Schilling: Bildpublizistik (wie Anm. 45), S. 231-236.
} 
Erschienen in: Anthropologie und Medialität des Komischen im 17. Jahrhundert (1580-1730), S. 429-463, https://doi.org/10.1163/9789401205993 019, Leiden, Brill, 2015

zwischen Mann und Frau zu imaginieren. Indem satirische Einblattdrucke das Andere der Norm in komischer Absicht darstellen, generieren sie eine Diskurssituation, innerhalb derer die gesellschaftlichen Rollenzuweisungen mittels eines geistreichen Spiels de- und rekonstruiert werden können und eröffnen zwischen den Polen ,Normvollzug' und ,Normdurchbrechung' ein weites Spannungsfeld divergierender Denk- und Handlungsoptionen.

\begin{abstract}
Für das 17. Jahrhundert ist eine größere Zahl von Einblattdrucken überliefert, die ,typische' Verstöße gegen eheliche Normen satirisch denunzieren. Sie richten sich nicht nur, aber vor allem gegen Ehefrauen, denen spezifisch weibliche Laster sowie ein die zeitgenössische Geschlechterordnung durchbrechender Herrschaftsanspruch unterstellt werden. In Anlehnung an Darstellungsmodi des mundus inversus reflektieren die genannten Drucke die Auseinandersetzung mit Normen ehelichen Zusammenlebens, wie sie durch Ehelehren theoretisch fundiert und in der frühneuzeitlichen ,Policey' pragmatisch reguliert erscheinen und gewinnen dadurch, so scheint es zunächst, eine primär moraldidaktische und sozialdisziplinierende Funktion. Am Beispiel einiger in Nürnberg veröffentlichter Scherzmandate wird im vorliegenden Beitrag der Frage nachgegangen, ob die in Text und Bild sich manifestierenden ,Inversionsfiguren' ehelichen Verhaltens darüber hinaus bislang unerforschte Funktionsmöglichkeiten eröffnen. Dabei zeigt sich, dass der satirische Charakter der Publikationen sowie die gesellige Kommunikationssituation, innerhalb derer sie ihre Wirkung entfaltet haben dürften, eine ausschließlich auf die moralische und disziplinierende Dimension abhebende Interpretation der untersuchten Scherzmandate als reduktionistisch erscheinen lassen. Indem diese das Andere der Norm in komischer Absicht darstellen, generieren sie nämlich nicht nur ein Handlungsfeld divergierender Handlungsmuster, sondern zugleich einen Diskursraum, innerhalb dessen Geschlechterrollen auf nicht sanktionierbare Weise de- und rekonstruiert werden können.
\end{abstract}

